IZA DP No. 6858

Labor Market Impacts of a Large-Scale Public Works Program: Evidence from the Indian Employment Guarantee Scheme

Laura Zimmermann

September 2012 


\title{
Labor Market Impacts of a Large-Scale Public Works Program: Evidence from the Indian Employment Guarantee Scheme
}

\author{
Laura Zimmermann \\ University of Michigan \\ and IZA
}

\section{Discussion Paper No. 6858 \\ September 2012}

\author{
IZA \\ P.O. Box 7240 \\ 53072 Bonn \\ Germany \\ Phone: +49-228-3894-0 \\ Fax: +49-228-3894-180 \\ E-mail: iza@iza.org
}

\begin{abstract}
Any opinions expressed here are those of the author(s) and not those of IZA. Research published in this series may include views on policy, but the institute itself takes no institutional policy positions. The IZA research network is committed to the IZA Guiding Principles of Research Integrity.

The Institute for the Study of Labor (IZA) in Bonn is a local and virtual international research center and a place of communication between science, politics and business. IZA is an independent nonprofit organization supported by Deutsche Post Foundation. The center is associated with the University of Bonn and offers a stimulating research environment through its international network, workshops and conferences, data service, project support, research visits and doctoral program. IZA engages in (i) original and internationally competitive research in all fields of labor economics, (ii) development of policy concepts, and (iii) dissemination of research results and concepts to the interested public.
\end{abstract}

IZA Discussion Papers often represent preliminary work and are circulated to encourage discussion. Citation of such a paper should account for its provisional character. A revised version may be available directly from the author. 
IZA Discussion Paper No. 6858

September 2012

\section{ABSTRACT}

\section{Labor Market Impacts of a Large-Scale Public Works Program: Evidence from the Indian Employment Guarantee Scheme*}

Recent years have seen an increasing interest in using public-works programs as antipoverty measures in developing countries. This paper analyzes the rural labor market impacts of the Indian National Rural Employment Guarantee Scheme, one of the most ambitious programs of its kind, by using a regression discontinuity design. I find that privatesector wages increase substantially for women, but not for men, and that these effects are concentrated during the main agricultural season. In contrast, there is little evidence for negative private employment effects.

JEL Classification: $\quad H 53,138, \mathrm{~J} 22, \mathrm{~J} 23, \mathrm{~J} 38$

Keywords: public works program, National Rural Employment Guarantee Scheme, NREGA, NREGS, India, regression discontinuity design

Corresponding author:

Laura Zimmermann

Department of Economics

University of Michigan

611 Tappan Street

Ann Arbor, MI 48109-1220

USA

E-mail: Ivzimmer@umich.edu

\footnotetext{
* I thank Manuela Angelucci, Raj Arunachalam, Arnab Basu, Gaurav Khanna, David Lam, Jeff Smith, Dean Yang, and participants of the University of Michigan Informal Development Seminar, the University of Michigan Labor Lunch, and the University of Michigan Summer Seminar for valuable comments, feedback and suggestions. Ravi Srivastava provided helpful information about the use of the Planning Commission index for NREGS district assignment. Abhiroop Mukhopadhyay was of major help with data-related questions.
} 


\section{Introduction}

Large-scale public works programs have fallen out of favor as effective active labor market policies in developed countries. Such government programs typically prove unable to raise workers' human capital, and are in danger of crowding out privatesector jobs. $^{1}$ In developing countries, on the other hand, recent years have seen a resurgence of interest in government employment programs and employment guarantee schemes, although with different intentions: Public-works programs are increasingly seen as a potential silver bullet for reducing poverty by functioning as conditional cash transfer programs. Rural labor markets often lack adequate employment opportunities during the agricultural off-season, and credit markets are still absent or incomplete in many areas. This means that the rural poor face severe challenges of unemployment, underemployment and lack of access to credit, making it difficult for households to smooth consumption (see e.g. Lal et al. 2010).

Standard government programs that target these populations in developing countries have often been quite ineffective, however. One important reason for this is that governments in developing countries have to deal with a multitude of problems in administering these programs: First, an effective targeting of vulnerable populations is often difficult. Reliable and up-to-date information on households is often incomplete, leading to many eligible households not being captured in administrative records. Additionally, corruption is often widespread and further dilutes the targeting of programs to the core population. Second, support for rural households often needs to be flexible and quick in response to severe shocks, but many government programs are implemented sluggishly. Third, government programs often have a very centralized structure that may work poorly in specific local contexts (see e.g. Lal et al. 2010).

Public works programs seem to be able to deal with all of these problems: They

\footnotetext{
${ }^{1}$ For an overview of active labor market policies see e.g. Kluve (2010) for Europe.
} 
allow households to self-select into manual labor work, which abolishes the need for other formal eligibility rules or a complete roster of the target population. They also provide great amounts of flexibility since households can sign up for the program if and when they need it, and the programs can potentially be adapted to local conditions with the help of local governments and grassroot-level involvement (see e.g. Subbarao 1997).

We still know relatively little about how well such programs work in developing countries and about how they affect the workings of the rural labor markets, however. ${ }^{2}$ One program that is attracting considerable academic and policy-related interest is the Indian National Rural Employment Guarantee Scheme (NREGS). With a legal guarantee of 100 days of manual work per year provided by the central government for every rural household, NREGS is one of the biggest and most ambitious public works programs in the world, making it an important program to study.

This paper contributes to a growing literature of empirically well-identified research on the impacts of public works programs in developing countries by analyzing the impact of NREGS on rural Indian labor markets. The empirical strategy exploits the fact that while the program was phased in in a non-random manner, it was first introduced in the poorest districts according to an underlying development index. This allows the use of a regression discontinuity framework.

I find that NREGS has very limited labor market impacts for men, but has led to a substantial increase in the private-sector casual wage for women. These wage impacts are concentrated in the agricultural main season. There are no statistically significant effects on public or private sector casual employment, suggesting that there is little room for the wage results to be driven by a changed selection into the workforce.

\footnotetext{
${ }^{2}$ See e.g. Basu (2011), Besley and Coate (1992), Datt and Ravallion (1994) for some examples of theoretical and empirical analyses. Most of the existing empirical literature on the topic lacks a credible causal identification strategy, however.
} 
Many employment coefficients are relatively imprecisely estimated, however, and are consistent with an increase in public-sector employment mainly during the agricultural off-season and some crowding out of casual private-sector work. These results are consistent with NREGS work being especially attractive during the agricultural off-season when there are relatively few private-sector jobs, while public-sector employment provides an outside option during the agricultural season that induces upward pressure on private-sector wages. They also complement existing evidence that NREGS employment is especially attractive for women.

The rest of this paper is structured as follows: Section 2 provides some background on the characteristics of NREGS. Section 3 sets up some hypotheses regarding the impact of the program based on a simple model. Section 4 describes the rollout of the program and how it can be used in a regression discontinuity framework, while section 5 discusses the data used and the empirical specifications. Section 6 presents the main results and some extensions. Section 7 concludes.

\section{Background}

\subsection{Theoretical Program Characteristics}

The National Rural Employment Guarantee Scheme (NREGS) ${ }^{3}$ is one of the most ambitious government development programs in the world. ${ }^{4}$ It is based on the National Rural Employment Guarantee Act (NREGA) that legally guarantees each rural household up to 100 days of public-sector work a year ${ }^{5}$ at the minimum wage. There are no formal eligibility rules other than that the household lives in a rural area and their

\footnotetext{
${ }^{3}$ The program was renamed to Mahatma Gandhi National Rural Employment Guarantee Scheme in 2009 .

${ }^{4}$ For more details on the scheme see e.g. Dey et al. (2006), Government of India (2009), and Ministry of Rural Development (2010).

${ }^{5}$ The year is the financial year and starts on April 1.
} 
members are prepared to do manual work at the minimum wage. Households can apply for work at any time of the year, and men and women are paid equally. At least one third of the NREGS workforce is required to be female.

NREGS projects focus mainly on the improvement of local infrastructure and on anti-drought measures and need to be carried out without the help of contractors or machines. Paid wages are the state minimum wage for agricultural laborers, although NREGA specifies a floor minimum wage. At the introduction of the scheme, this floor wage was Rs 60 per day. It has been raised over time, and was Rs 120 per day in 2009. In most states wages are paid on a piece-rate basis where the rates are supposed to be adjusted such that a typical worker working for 8 hours will earn the minimum wage. Wages must be paid within 15 days of the day the work was performed, and are supposed to be paid on a weekly basis.

\subsection{Empirical Working of the Program}

How well the ambitious features of NREGS work in reality has been of large interest to researchers, NGOs and the press right from the beginning of the scheme. Qualitative and descriptive research suggests that NREGS is implemented well enough to generate substantial benefits for the poor: A number of studies document, for example, that NREGS seems to be successful in providing employment during the agricultural offseason and after idiosyncratic shocks, allowing households to earn additional income and increase their food and durable expenditures (see e.g. Centre for Science and Environment 2008, Institute of Applied Manpower 2007, NCAER-PIF 2009).

Some papers specifically stress the benefits NREGS provides for women. Khera and Nayak (2009), for example, use a survey of 1060 NREGS workers in six North-Indian states to study the impact the scheme has had on women, and conclude that NREGS has improved women's access to jobs with reasonable wages and working conditions. 
Narayan (2008) and Jeyaranjan (2011) document similar benefits for women in their case studies in Tamil Nadu.

While these studies suggest substantial benefits for the rural poor in India, they also stress widespread practical limitations and violations of the provisions in the National Rural Employment Guarantee Act: Muster rolls are often faulty and include ghost workers, for example, wages are often paid with long delays and may not conform to the state minimum wage (Centre for Science and Environment 2008, Institute of Applied Manpower 2007, Khera 2009, NCAER-PIF 2009, Samarthan Centre for Development Support 2007). Additionally, many local governments seem to lack the technical expertise to propose useful local projects. Big landowners have also repeatedly complained about labor shortage and demanded NREGS work be banned during the peak agricultural season (Dutta et al. 2012, Institute of Applied Manpower 2007, NCAER-PIF 2009).

Much existing economics research on NREGS either focuses on a specific Indian state or on a specific aspect of the program. Johnson (2009a) looks at the impact of rainfall shocks on the take-up of NREGS in the Indian state Andhra Pradesh, and finds that participation in public-works projects increases when rainfall is lower than expected, so that NREGS seems to provide a safety net for rural households. Johnson (2009b) finds that the working of NREGS in Andhra Pradesh does not seem to be strongly affected by the parties in power at the local level, suggesting that the program is not vulnerable to extensive political pressures in this state. Johnson et al. (2009) also provide a detailed descriptive overview of the working of the program in Andhra Pradesh on the basis of administrative data for the state. Niehaus and Sukhtankar (2011a and 2011b) analyze the existence and characteristics of corruption in the implementation of NREGS in the Indian state Orissa, and find that an increase in the minimum wage was not passed through to workers. 
Dutta et al. (2012) use nationally representative data from 2009/10 to study the effectiveness of reaching the target population. They find that demand for NREGS often far outstrips supply and that the rationing of projects is especially common in poorer states.

The papers that are most closely related to the analysis in this paper are Imbert and Papp (2012) and Azam (2012). Imbert and Papp (2012) use a difference-in-difference approach to look at the program's impact on wages and employment. They compare districts which received the program early to districts that had not yet received the program in 2007/08. Using nationally representative data, they find that NREGA increases employment by 0.3 days per prime-aged adult per month and increases privatesector wages by 4.5 percent. Their results are concentrated during the agricultural offseason. Azam (2012) also uses a difference-in-difference approach, and finds that public sector employment increases by 2.5 percent while wages for males and females increase by 1 and 8 percent, respectively.

The difference-in-difference strategy requires both papers to make the parallel-trend assumption that labor market outcome trends would have been similar in early and late NREGS districts in the absence of the program. Given the non-random rollout of the program according to poverty criteria this assumption is unlikely to hold, however, which could substantially affect their results. The regression discontinuity approach used in this paper, on the other hand, does not require such an assumption and therefore provides cleaner empirical identification of the impacts of NREGS. As it turns out, the choice of the identification strategy significantly affects the seasonality of the wage impacts. ${ }^{6}$

To fix ideas about the expected impacts of the scheme, it is useful to set up a simple

\footnotetext{
${ }^{6}$ Imbert and Papp's (2012) wage impacts, for example, are concentrated during the agricultural offseason, whereas the RD results in this paper suggest that wage effects are strongest in the agricultural main season. Since both papers are using the same data sources and sample restrictions, the main difference is the chosen identification strategy.
} 
theoretical framework.

\section{A Simple Model of the Indian Labor Market}

Suppose the Indian rural labor market can be characterized as a perfectly competitive market. Workers can choose to either work in the informal private sector at wage $w_{p}$ or to remain out of that market by working in a family business, working in publicworks projects or being out of the labor force. The private market labor supply curve $L_{S}\left(w_{p}, \overline{w_{r}}\right)$ is increasing in the private-sector wage $w_{p}$, and also depends on the threshold reservation wage $\overline{w_{r}} \cdot \overline{w_{r}}$ captures the reservation wage of the marginal worker who is indifferent between working in the private sector and the most attractive alternative form of employment. The private market labor demand curve $L_{D}\left(w_{p}\right)$ is weakly decreasing in $w_{p}$. The competitive market equilibrium occurs where $L_{S}\left(w_{p}^{*}, \overline{w_{r}}\right)=L_{D}\left(w_{p}^{*}\right)$.

The introduction of NREGS makes working in a public works project more attractive since the paid minimum wage $\underline{w}$ is assumed to be higher than $w_{p}^{*}$. This is a consequence of poor enforcement of existing minimum wage laws in India. As the program is demand-driven, in a world without labor market frictions like rationing every worker who wants to work under NREGS can also do so. This means that workers' reservation wages rise for all workers $i$ for whom $w_{r i} \leq \underline{w}$, leading to excess demand for labor at $w_{p}^{*}$. The new equilibrium will occur at $w_{p}^{*^{\prime}}=\underline{w}$, and employment is $L_{D}\left(w_{p}^{*^{\prime}}\right)$, which is weakly smaller than $L_{D}\left(w_{p}^{*}\right)$ depending on the slope of the labor demand curve. This outcome is equivalent to the standard textbook case of the introduction of a minimum wage in a perfectly competitive labor market. If NREGS work is rationed, as empirical research suggests, the upwards pressure on wages will be lower, and the negative impact on private-sector employment less negative, but the qualitative results remain the same: Overall, the introduction of NREGS should raise private-sector wages 
and weakly decrease private-sector employment.

Descriptive empirical work on NREGS suggests that the impacts of the employment guarantee scheme on the Indian labor market should differ by gender and season. NREGS employment is especially attractive for women for two reasons: First, female private-sector wages are typically significantly lower than those of males, whereas men and women are paid the same wage under NREGS. Additionally, some studies have found that in wide areas of the country NREGS wages are not much higher than male private-sector wages, and may often even be lower, meaning that NREGS employment is not an attractive outside option for many men (see e.g. Dutta et al. 2012). Second, the program stipulates that at least one third of the NREGS workforce at any time should be female, stressing the government's commitment to employing women. These factors suggest that the predictions of the simple private labor market model should apply much more to women than to men. There may be no wage and employment impacts of NREGS for men if the scheme's wages are not higher than average baseline private-sector wages.

Seasonality also plays an important role for the likely impacts of the employment guarantee scheme. As pointed out above, workers seem to be especially reliant on NREGS work during the agricultural off-season when there are few private-sector jobs, but agricultural landowners seem to feel threatened enough by the program to have repeatedly demanded that NREGS work not be available during the harvesting season. This suggests that the above model should mainly apply during the main agricultural season when workers have the choice between private-sector and NREGS employment, but less so during the agricultural off-season. Additionally, labor demand is likely to be quite inelastic during the agricultural peak season. In consequence, the introduction of NREGS should lead to higher private-sector wages during the harvesting season, with little or no negative impacts on private-sector employment, but should not be 
expected to have major impacts on the private labor market during the off-season. Taken together with the gender aspect, these effects should be much more pronounced for women than for men.

This framework clearly oversimplifies reality. Other papers like Imbert and Papp (2012) develop more elaborate models based on micro-foundations, for example. Additionally, two theoretical papers deal in depth with the potential impacts of the employment guarantee scheme in the Indian case. The models of the rural labor market in India in Basu (2002) and Basu (2011) suggest that the introduction of an employment guarantee scheme will raise agricultural wages, but reduce the employment of workers under long-term contracts and instead increase the number of workers reliant on shortrun employment and public works projects. The overall welfare implications of this are ambiguous.

Most of the additional assumptions made in these more elaborate models cannot be easily tested with the available data, however, and are sometimes controversial in the literature. ${ }^{7}$ This suggests that it may be preferable to keep the model of the Indian labor market as simple as possible. ${ }^{8}$

\footnotetext{
${ }^{7}$ The models in Basu (2002) and Basu (2011), for example, are built on the existence of two types of workers: those with long-run contracts, and those with short-run contracts. While the papers cite some evidence of the existence of such long-run contracts in some parts of India, other papers like Kaur (2012) argue that daily labor contracts are the norm in Indian rural labor markets. Imbert and Papp (2012) focus heavily on small farmers with simultaneous labor supply and demand decisions without saying much about how common this type of workers is relative to the number of landless laborers.

${ }^{8}$ Additionally, the empirical results for employment in this paper are often not precisely enough estimated to test detailed predictions about the private employment responses to NREGS.
} 


\section{Program Rollout and Regression Discontinuity Design}

\subsection{Program Timeline and Details of the Rollout}

The National Rural Employment Guarantee Act (NREGA), which forms the legal basis for NREGS, was passed in the Indian Parliament in August 2005 and lays down the characteristics of the program and the entitlements of workers under the employment guarantee scheme. NREGS came into force in February 2006 in the first 200 districts. The scheme was then extended to the rest of the country in two steps: An additional 130 districts received the program in April 2007, and all remaining rural districts started NREGS in April 2008. This means that since 2008 the scheme operates in 99 percent of Indian districts (the scheme excludes districts with a 100 percent urban population) (Ministry of Rural Development 2010). I will refer to the district phases as Phase 1, Phase 2, and Phase 3, respectively. Taking into account the rollout timing is important for the empirical identification strategy.

The general government documents claim that NREGS was rolled out to the poorest districts first, but are vague about the algorithm the government used to decide which districts would receive the program in which phase. While the actual algorithm is not publicly available, institutional knowledge suggests a plausible algorithm since the Indian Planning Commission explicitly states the method that was used for treatment assignment of an earlier much smaller and less ambitious temporary government program aimed at less developed districts. ${ }^{9}$ This algorithm is supposed to ensure political fairness of resource allocation across states and within states in various ways. Given the importance of NREGS and the huge political interest and awareness it created among policymakers at all levels as well as NGOs and the press, it seems very likely that the

\footnotetext{
${ }^{9}$ See e.g. Planning Commission (MLP Division) 2003 for RSVY district assignment.
} 
Indian government adhered to these political fairness norms in the allocation of treatment districts for NREGS as well. A number of NGOs and well-known individuals were actively campaigning for the introduction of an employment guarantee scheme like NREGS, and have been closely monitoring the working of the program since its introduction. ${ }^{10}$ The fact that neither the press nor NGOs and other experts complained about district allocations suggests that while there may have been some slippage in following a set algorithm, manipulation was not rampant. This is especially significant because the program was originally planned to be phased in much more slowly, which would have implied considerable benefits of receiving the program early rather than in one of the later phases.

Overall, it therefore seems plausible that NREGS district assignment would have made use of the existing allocation algorithm of earlier programs. This algorithm has three provisions: First, each state receives at least one treatment district regardless of the state's eligibility for the program based on other criteria. ${ }^{11}$ This means that government programs like NREGS operate even in the richest Indian states. Second, the number of districts that are allocated to a given state is proportional to the prevalence of poverty across states. This mechanism ensures that the number of districts allocated to a given state is somewhat proportional to the percent of India's poor people living in that state. ${ }^{12}$ Third, within a state districts are chosen based on a development ranking by the Planning Commission, so that poor districts are chosen first. ${ }^{13}$

\footnotetext{
${ }^{10}$ Jean Dreze and Reetika Khera have been especially involved in NREGS from the beginning. Examples of monitoring include awareness campaigns for workers' rights under NREGS, survey data collection to find out about common challenges and violations of the law, suing governments for NREGA violations, and drawing attention to corruption. See e.g. Samarthan Centre for Development Support 2007.

${ }^{11}$ Union territories are typically excluded in these programs.

${ }^{12}$ The government term for this is 'incidence of poverty'. While there is no official definition of this term, it seems to be a combination of the poverty headcount ratio within a state (the percent of people living below the poverty line) and state population, since large states usually receive more districts than very poor but less populous states, although the mapping is not exact.

${ }^{13}$ See Planning Commission (2003). Phase 1 allocation assignment had an additional feature: In that phase, all districts on an existing list of districts strongly affected by left-wing terrorism received
} 
According to this proposed algorithm, a number of eligible districts was therefore allocated to states first in a given phase of the NREGS rollout, and districts within states were then supposed to be chosen based on the Planning Commission ranking. ${ }^{14}$

Table 1 gives an overview of how well the proposed algorithm predicts NREGS receipt in the first and second phase for 17 major Indian states. ${ }^{15}$ The first and third columns provide the number of districts that a given state was assigned in Phase 1 and Phase 2, respectively, while the second and fourth columns show the number of districts in a given state that received NREGS although they should not have received the program based on the specified algorithm in a given phase. As Table 1 shows, the algorithm cannot explain the treatment status of 22 of 183 districts that received NREGS in phase 1, and of 25 of 106 districts in Phase 2, so there was some slippage in district assignment. Still, the prediction success rates for Phase 1 and Phase 2 are about 88 percent and 76 percent, respectively.

While Table 1 suggests that the proposed algorithm works quite well for predicting Phase 1 and Phase 2 district allocations, there are a number of potential problems. These are discussed in the next section.

NREGS regardless of their rank. This means that in the within-state allocations, terrorist-affected districts were prioritized.

${ }^{14}$ The all-India number of treatment districts in each phase, 200 and 130, do not seem to have been chosen to accommodate state or district demands for a certain number of treatment districts. 200 was the number of districts the Planning Commission suggested for an earlier development program which never really took off. The number 130 , on the other hand, seems to have been adapted since a number of states that had received many NREGS districts in the first phase had only few untreated districts left that could be treated in Phase 2.

${ }^{15}$ Rank data is available for 447 of 618 districts in India. Data for the index creation was unavailable in some states. A former member of the Planning Commission says that in these states state governments may have had considerable say in district allocation, so in the absence of a general rule treatment status in these states is likely to be endogenous. I therefore exclude these states from my analysis. 


\subsection{Regression Discontinuity Design}

Given that the proposed algorithm of NREGS treatment assignment has a two-step procedure, where the number of eligible districts is allocated to states first, and districts are then chosen within a state to fill up this number of slots based on their rank, the generated cutoffs that can be used for a regression discontinuity (RD) analysis are state-specific. Two cutoffs can be empirically identified: the cutoff between Phase 1 and Phase 2, corresponding to Phase 1 treatment assignment, and the cutoff between Phase 2 and Phase 3, which is equivalent to the Phase 2 rollout of the program. Since the dataset that I will be using in my empirical analysis was collected at a time when NREGS had been rolled out to Phase 1 and Phase 2 districts, but not yet to Phase 3 districts, the cutoff between Phase 2 and Phase 3 can be used to analyze the impact of the government program. I therefore focus on this cutoff in the remainder of this paper, but corresponding figures and tables for the other cutoff can be found in the appendix. $^{16}$

Treatment cutoffs differ by state, so for the empirical analysis ranks are made statespecific and are normalized so that a district with a normalized state-specific rank of zero is the last district in a state to be eligible for receiving the program in Phase 2 . This makes it easy to pool the data across states to estimate the treatment effect at a common discontinuity. Negative numbers are assigned to districts with lower ranks than the cutoff rank, whereas positive numbers are assigned to the districts that are too developed to be eligible according to the district ranking and will function as control districts in my empirical analysis.

Figure 1 shows the number of observations at each state-specific rank for Phase 2

\footnotetext{
${ }^{16}$ This other cutoff tests the time pattern of NREGS receipt, that is whether the length of time that a district has had the program matters for labor market outcomes. The power to detect statistically significant effects is likely to be much lower in this case since both types of districts have had access to NREGS for about a year at the time of the data collection. I find no significant effects at this margin for any outcomes or specifications.
} 
district assignment. It reveals that all 17 states used in the analysis have at least one district receiving NREGS in Phase 2, but that only few states have districts further away from the 0 cutoff. While this pattern mostly reflects that there are only few states with a large number of districts, a number of states are also fully treated after Phase 2 assignment so that they have no Phase 3 districts and therefore no positive-rank districts in Figure 1.

Figure 1 reports observations based on the predicted NREGS receipt of the proposed algorithm. As Table 1 shows, however, actual program receipt does not completely follow this assignment. Therefore, the empirical identification strategy is a fuzzy RD design. The fundamental assumption of the RD design is that districts that were just poor enough to receive the program, and districts that were just too rich to be included are similar to each other in terms of unobserved characteristics, so that outcome differences in these two different types of districts are solely attributable to the introduction of the unemployment guarantee scheme.

In order for the RD design to be valid, districts must have imperfect control over their treatment status in a given phase (Lee 2008). In this specific case, this implies that states and districts should not have been able to manipulate either the index variable used to rank districts, or the number of districts that were allocated to a specific state. Otherwise, districts close to the cutoff on either side are not plausibly similar to each other in terms of unobserved characteristics, but differ on characteristics such as perceived benefit from the program.

That states or districts were able to manipulate the index variable values seems unlikely. First, the index was constructed based on somewhat dated available information: The Planning Commission used data from the early to mid-1990s for the ranking of districts, rather than collecting current information from districts. This limits the possibility for districts or states to strategically misreport information. Second, the 
ranking had originally been used to target earlier development programs for especially poor districts, although with lower cutoffs of 100 and 150 districts, which implied lower state-specific cutoffs as well. So if districts were able to act strategically, the incentive would have been to be among the 150 poorest districts, but not among the 200 poorest districts used for NREGS in the first phase, and certainly not among the 330 poorest districts that received NREGS in either Phase 1 or Phase 2. Third, the creation of the index from the raw data by the Planning Commission is done in a very transparent way. The Planning Commission report outlines the exact procedure with which the index was created, and also lists the raw data for all districts, so that the composite index as well as the district ranking can be perfectly replicated. This implies that there was no room for manipulation at the level of the creation of the district rank variable.

Figures 2 and 3 look more closely at the distribution of index values over ranks. Ideally, we would like the assignment variable to be continuous at the cutoff, since discontinuities at the cutoffs are typically taken as signs of potential manipulation (McCrary 2008). Figure 2 shows the relationship between the poverty index value and the assigned rank by the Planning Commission for all 447 districts for which data is available. Across India, the distribution of poverty index values is smooth and continuous across ranks. As the chosen cutoffs are state-specific, Figure 3 plots the relationship between the Planning Commission's index and the normalized state-specific ranks for the Phase 2 cutoff. For most states, the poverty index values seem pretty smooth at the cutoff of 0 . Overall, these patterns suggest that manipulation of the underlying poverty index variable is not a big concern.

While the manipulation of the data used to create the district ranking seems unlikely, it is more difficult to rule out that the allocation of treatment districts across states was subject to political influence. While it is known which data source was usually used to estimate state-wide poverty measures, it is unknown which exact measure was taken 
as the 'incidence of poverty' that determines state allocations of treatment districts in government development programs. The current analysis takes the actual state allocations as the correct allocations. This implies that the true RD design could be fuzzier than the one used here if there was imperfect compliance with the state allocations. Since I am using state-specific cutoffs for my RD design, this only matters for the validity of my empirical results if states did not just lobby to maximize the number of treatment districts allocated to them, but were able to precisely control which and how many of their districts received treatment. This seems highly unlikely, but in that case the results should be taken as upper bounds of the true treatment effects since presumably states would have had an incentive to introduce NREGS in districts that were expected to benefit substantially from the new scheme.

With a fuzzy RD design, we also need to verify that there is indeed a discontinuity in the probability of receiving NREGS at the cutoff values for Phase 2 NREGS districts. Figure 4 shows this graphically for the normalized state-specific cutoff for Phase 2. It plots the probability for receiving NREGS in the given phase for each bin, as well as fitted quadratic regression curves and corresponding 95 percent confidence intervals on either side of the cutoff. The graph shows that the average probability of receiving NREGS jumps down at the discontinuity. This suggests that there is indeed a discontinuity in the probability of being treated with the employment guarantee scheme at the cutoff.

\section{Data and Empirical Specification}

\subsection{Data and Variable Creation}

The data used in this paper comes from household surveys collected by the National Sample Survey Organisation (NSSO). These surveys are representative of the Indian 
population, and drawn from the population in a two-stage stratified sample design. In the first stage, villages are selected, and individual households within these villages are sampled in the second stage. The dataset that can be used to analyze the impact of NREGS on wages and employment is the 64th round of NSS data, which was collected from July 2007 to June 2008. It has a sample size of about 120,000 households and interviews were carried out over the course of a year in four sub-rounds, each spanning three months. By this time, NREGS had just been rolled out to Phase 2 districts in April 2007. ${ }^{17}$ Phase 3 districts received the program in April 2008, although general delays in implementation suggest that Phase 3 districts can be treated as control districts even for the last three months of the survey. ${ }^{18}$

The dataset collects wage and employment information as well as a number of sociodemographic characteristics. Additionally, a sample of households are interviewed in a given district in every sub-round, if possible. While the household data is strictly cross-sectional, this means that at the district level it is possible to generate a subround panel with up to four observations per round. ${ }^{19}$ I will exploit this feature of the data empirically by aggregating individual-level information up to the district level for each sub-round separately. ${ }^{20}$ In addition to increasing sample size, this has the added advantage that it is possible to look at seasonal differences in the impact of NREGS on wages and employment.

Consistent with other NREGS papers, I restrict my sample to individuals of prime age (18-60) who are living in rural areas and have at most secondary education. The

\footnotetext{
${ }^{17}$ Unfortunately, there is no NSS survey data available that was collected at a time when NREGS was only operating in Phase 1 districts and that has the large sample size needed for district-level analysis. The NSSO alternates between 'thick rounds' with large sample sizes like the 64th round, and 'thin rounds' that have a much smaller sample size.

${ }^{18}$ See e.g. Imbert and Papp (2012). The results reported in this paper are qualitatively the same when these potentially contaminated control group observations are excluded.

${ }^{19}$ While the panel is not perfectly balanced in practice, most districts are interviewed in every season.

${ }^{20}$ This feature of the data has also been exploited in other NREGS papers like Imbert and Papp (2012).
} 
NSS employment module asks detailed questions about an individual's work status in the last 7 days. I use these questions to create various employment and wage variables, focusing on casual jobs. Employment measures are dummy variables equal to 1 if an individual worked at all in a job of a given characteristic in the past 7 days, and 0 otherwise. I add up the value of wages received in cash and kind for private-sector jobs and divide it by the amount of time spent in that type of work to create a daily private wage for workers. I then aggregate the labor market measures up to the district-subround level using sampling weights.

Data from the 61st round (July 2004-June 2005) is used as baseline information. In a typical RD design, baseline information is not necessary for empirical identification, but controlling for baseline characteristics can increase the precision of the estimates by reducing residual variance. This is especially true in this case: NREGS cutoffs are based on district rankings using information from the early to mid-1990s, whereas the first districts received the program in 2006. Since districts close to the cutoff on either side in the early 1990s are likely to have been more similar to each other at the time the raw data was collected than they are 15 years later, controlling for baseline information of the outcome variables will help to control for differential district development during the 1990s and early 2000s.

\subsection{Empirical Specification}

I control for the lagged outcome variables by including the baseline outcome variable as an additional regressor. ${ }^{21}$ As the number of observations near the cutoff is limited, I use parametric regressions to estimate the impact of NREGS empirically. ${ }^{22}$ To test

\footnotetext{
${ }^{21}$ An alternative to this is to have the outcome variable be the difference between post- and preNREGS time periods, but this option is nested in the other specification since this option constrains the coefficient on the baseline outcome variable to be 1 .

${ }^{22}$ This is in line with the advice in Lee and Lemieux (2009) in such a situation.
} 
the robustness of the estimates, all main result tables show the estimated coefficients for linear and quadratic regression curves in the running variable with and without constraining the slope of the curves to be the same on either side of the cutoff. ${ }^{23}$ I also drop Phase 1 districts to ensure that the parametric estimates of the treatment effects are not affected by districts that are far away from the cutoff. It is important to note that since the RD design depends on observations being close to the cutoff for identification it is impossible to compare Phase 1 and Phase 3 districts since these will be far apart from each other by design. In contrast to difference-in-difference estimations, the RD design therefore cannot estimate the impact of having had the program for up to two years compared to the control group.

The equation below shows the regression equation for the most flexible specification with a quadratic regression curve with the slope not constrained to be identical on both sides of the cutoff:

$$
\begin{gathered}
y_{i j k}=\beta_{0}+\beta_{1} \text { rank }_{i j}+\beta_{2} \text { rank }_{i j}^{2}+\beta_{3} \text { nregs }_{i j}+\beta_{4} \text { nregs } * \text { rank }_{i j}+\beta_{5} \text { nregs } * \operatorname{rank}_{i j}^{2}+ \\
\beta_{6} \text { baseliney }_{i j}+\eta_{j}+\epsilon_{i j k}
\end{gathered}
$$

where the subscripts refer to individual $i$ in district $j$ in season $k . y$ is an outcome variable of interest, whereas nregs is an indicator variable equal to 1 if a district received NREGS in a given phase, and zero otherwise. Since we are dealing with a fuzzy RD rather than a sharp RD, this is instrumented with predicted NREGS receipt based on the state-specific algorithm. rank is a district's rank based on the state-specific normalized index, and $\eta$ are state fixed effects. ${ }^{24}$ The coefficient of interest is $\beta_{3}$. In

\footnotetext{
${ }^{23}$ F-tests reject the null hypothesis that higher-order polynomials add important flexibility to the model. More flexible models also tend to be unstable in the second stage of the two-stage least squares estimation procedure, although the estimated coefficients are often qualitatively similar to the quadratic results. The quadratic flexible specification only statistically outperforms the linear flexible specification in some instances.

${ }^{24}$ Including sub-round fixed effects often makes the first stage estimation highly unstable since a number of employment outcomes are highly correlated with specific seasons. I therefore don't include season-fixed effects, although including them has no big impacts on the second-stage results.
} 
all empirical specifications, standard errors are clustered at the district level. ${ }^{25}$ Results are reported for men and women separately.

\subsection{Summary Statistics}

Tables $2 \mathrm{~A}$ and $2 \mathrm{~B}$ present baseline wage and employment summary statistics for districts separately by phase for men and women respectively. As the Table 2A shows, early NREGA districts have lower baseline wages than later districts, consistent with the idea that NREGA was rolled out to the poorer districts first. The daily wage of a typical male casual worker of prime age with at most secondary education in an average Phase 1 district is about 47 rupees, whereas the corresponding wages are about Rs.53 and Rs.66 in Phase 2 and Phase 3 districts, respectively. Private-sector daily wages are very similar to overall casual daily wages. Public-sector wages are a lot higher than private wages in Phase 1 districts, where the average wage is about Rs.87. In later-phase districts the level of public-sector and private-sector wages are similar.

In general, however, it is very uncommon to work in the public sector in all districts: 0.3 percent of workers work in the public sector in a typical Phase 1 district in the week prior to the survey, and the corresponding numbers for Phase 2 and Phase 3 districts are 0.4 and 0.2 percent, respectively. In contrast, in all districts about 30 percent of males work in private casual jobs, and about 58 percent work in a family business or on the family farm. The remainder are males who are unemployed or out of the labor force.

Table $2 \mathrm{~B}$ shows that the situation for Indian women is qualitatively similar to that of men, but that women are about half as likely to work in casual jobs of any kind or

\footnotetext{
${ }^{25}$ The results from reweighting observations by their 2001 Census population size are qualitatively very similar to these results and therefore not presented here. This extension takes into account that district-averages will be more precisely estimated in large districts than in small ones since the individual-level data is representative of the Indian population.
} 
in family employment as men.

\section{Results}

\subsection{Main Results}

Figures 5 to 8 and Tables 3 through 8 present the main results of the impact of NREGS for men and women separately. ${ }^{26}$ The figures show the regression discontinuity design graphically for the probability of being employed in a public works program in the past 7 days, and for the private-sector daily casual wage earned in the past week. ${ }^{27}$ The outcome variables are the difference of post-NREGS outcomes and the baseline information, so one scatter point represents the increase in the average district outcome value over the span of two years in a given season. The regression lines are quadratic in the rank variable, with the slope allowed to differ between the two sides of the cutoff, and include no other control variables. The graphs also show the 95 percent confidence intervals. None of the figures show a statistically significant discontinuity in public employment or the earned private wage at the cutoff value 0 , suggesting that the impacts of NREGS on the Indian rural labor market are limited.

Tables 3 to 8 focus on different empirical specifications of the RD design in more detail. The two panels of each table show the results for the standard specification and the district-population weighted specification, respectively. All estimated models control for the baseline outcome variable and include state fixed effects. They also report the F-statistic of the first stage of the two-stage least squares models. One observation is a given district in a specific season.

Tables 3, 4 and 5 show the results for men. Table 3 demonstrates again that NREGS

\footnotetext{
${ }^{26}$ The main result tables for the Phase 1 cutoff can be found in the appendix.

${ }^{27}$ The graphs for private casual employment look qualitatively very similar and are excluded for brevity.
} 
does not seem to have a large impact on public-sector casual employment, the main outcome that we would expect to be majorly affected by the introduction of a large-scale employment guarantee scheme. The typical estimate is positive but small in absolute value and statistically insignificant. The coefficient estimate in column 1, for example, suggests that being in a NREGS district increases a rural prime-aged men's probability of having had a public-works job in the last 7 days by 0.1 percentage points. This translates into an increase of 14.5 percent since mean public employment is only 0.69 percent, but the effect is statistically insignificant.

Table 4 reveals that NREGS also does not seem to have a large impact on private casual employment. ${ }^{28}$ The estimated coefficients are negative, which is consistent with the idea that NREGS crowds out some private employment, but none of them are statistically significantly different from 0 . While the confidence intervals are typically quite wide and do include economically singificant magnitudes, these results taken together with those from Table 3 suggest that there is no significant change in the selection into the workforce as a result of NREGS.

Table 5 shows the corresponding results for the daily private casual wage. ${ }^{29}$ The outcome variable in columns 1 through 4 is the level wage earned, conditional on having earned a positive daily wage, whereas column 5 uses log wages. Since Tables 3 and 4 show little evidence for employment changes, any wage impacts of NREGS in these specifications should not be driven by selection issues. The specification in column 6 is the unconditional private daily wage. Similar to Table 3, the impact of NREGS on private wages is small in absolute value and statistically insignificantly different from zero. The estimated coefficient in the first column, for example, suggests that

\footnotetext{
${ }^{28}$ The impact of NREGS on the probability of being in family employment, not reported here, is positive for men and women, although imprecisely estimated. Family employment includes working on the family farm as well as in a family business.

${ }^{29}$ Since public-sector casual employment is very low, daily private casual wages are almost identical to total daily wages from casual labor.
} 
the private wage for men increased by about one rupee in treatment districts relative to control districts at the cutoff, while the average wage across districts is 66 rupees. There is no strong pattern even for the sign of the effect, and percent changes in the wage are also relatively small.

Tables 6,7 and 8 show the corresponding results for women. As Table 6 demonstrates, the impact of NREGS on the probability of being employed in a public works project for women is typically positive and larger than for men, although the estimates are relatively small in absolute magnitude and statistically insignificantly different from zero.

Table 7 shows that the impact of NREGS on casual private-sector employment for women is negative, which again is consistent with the competitive labor market assumption made in the simple model. As for men, the confidence intervals are typically wide and include economically significant magnitudes. Overall, Tables 6 and 7 therefore show that a change in the selection of women into the workforce again does not seem to be a major concern.

Table 8 suggests, however, that NREGS raises private-sector wages for casual work for women. The estimates of the first 5 columns are all positive, and either statistically significant at the 10 percent level, or just outside that level of significance. The specification in column 1, for example, says that NREGS increases the female daily casual wage, conditional on earning a positive amount, by about 11 rupees. Since the average daily wage is about 44 rupees for women, this translates into a wage increase of 25 percent. The magnitude of this effect is relatively robust across different statistical specifications, and also shows up in the $\log$ specification in column 5 . As column 6 shows, however, the wage increase seems to be confined to the conditional wages: The outcome variable in column 6 is the unconditional private-sector daily wage earned by women in the last 7 days, and the coefficients are small in absolute value and negative, 
although not statistically significant. These estimates suggest again that NREGS has not substantially affected the composition of women in private employment, but if at all, the effect is negative.

Existing evidence suggests that seasonal effects are important, with NREGS work being especially attractive during the agricultural off-season. Tables 9 and 10 report the corresponding results for women. ${ }^{30}$ Consistent with the existing literature, seasonality is treated quite crudely ${ }^{31}$ : The months July through December roughly correspond to major harvesting and planting seasons for most crops and in wide parts of the country, and are therefore treated as the agricultural main season. January through June, on the other hand, are assigned to be the agricultural off-season or dry season.

Table 9 shows that, consistent with existing evidence, public-sector employment picks up in the dry season, although the effects are not statistically significantly different from zero at conventional levels, whereas the main effects are typically small in absolute magnitude and negative. Table 10 reveals that the upward pressure on wages is confined to the main agricultural season rather than the dry season, and is quite substantial: The coefficients in column 1, for example, suggest that female private wages increase by 19 rupees during the agricultural season, but only by about 3 rupees during the dry season. Again, this is consistent with the idea that private-sector wages need to increase during the main agricultural season when NREGS is a viable outside option, but that there is no real impact on the Indian labor market during the dry season.

\footnotetext{
${ }^{30}$ The qualitative effects for men are similar, but again typically much smaller and statistically insignificant, so they are omitted here. Private casual employment results are also not reported here. They are always statistically insignificant, although, consistent with the wage results, the negative impact of NREGS on private employment is concentrated during the main agricultural season.

${ }^{31}$ See e.g. Imbert and Papp (2012)
} 


\subsection{Discussion}

Overall, these results suggest that NREGS only has a very limited influence on the Indian rural labor market, although in a number of empirical specifications the effects are not precisely enough estimated to rule out more substantial effects. These results are robust to a number of other specifications not reported here, like the inclusion of control variables and the exclusion of potentially contaminated Phase 3 districts due to the timing of data collection. ${ }^{32}$

Maybe most surprising is the fact that a large-scale public works program like NREGS does not seem to significantly increase the working age population's probability of having held a public works job in the past 7 days. Mean public employment is only 0.69 percent for men and 0.53 percent for women in Phase 2 and Phase 3 districts. So while some of the estimated coefficients are equivalent to increases in public employment on the order of magnitude of 15 times, statistical power is not big enough to precisely estimate such small effects in absolute magnitude. The reported confidence intervals in Tables 3 and 6 show that the empirical analysis can typically rule out increases in public employment above 2-3 percentage points. For such a large and ambitious program that aimed at providing flexible employment opportunities for a large portion of poor rural households, even this upper boundary seems like a relatively modest effect.

One potential explanation for these small effects is the time frame of the household survey. Since employment information is based on a 7-day recall window, it is by design much noisier than employment histories over a longer time horizon, although there should be no issues with recollection error. It is therefore useful to compare these estimates to expected effect sizes based on administrative data. While some papers have

\footnotetext{
${ }^{32}$ Phase 3 districts received NREGS in April 2008, whereas the data was collected between July 2007 and June 2008 and Phase 3 districts are treated as controls throughout in the main specifications.
} 
documented that administrative records are exaggerating the effectiveness of NREGS due to corruption issues (see e.g. Niehaus and Sukhtankar 2011a, b), the administrative records provide an upper bound on NREGS impacts.

According to administrative records, the employment guarantee scheme provided 1435.9 million person-days of employment in 1.78 million projects in the 330 Phase 1 and Phase 2 NREGS districts in 2007-2008. ${ }^{33} 61.15$ percent of this employment was given to women. The average daily wage paid was 75 rupees. This means that in a typical week, the scheme generated .0598 workdays in general, and .0699 workdays for women, and there were about 104 projects operating in the average district. In the NSS data, the number of public-works workdays in Phase 1 and Phase 2 districts are .0617 for prime-aged adults, and .0414 for women, respectively. This means that the NREGS employment generated for the chosen sample of prime-aged adults in this paper is in the same ballpark as that suggested by administrative sources, although my sample underestimates the employment effects for women relative to the official data. This, in turn, suggests that, if at all, the male results in this paper are overestimates, while the female results are underestimates of the effects we would expect from an analysis of NREGS using administrative data. At the same time, however, these back-of-theenvelope calculations also support the public employment results in this paper in that generated employment opportunities seem to be relatively modest at the local level.

In contrast to this, the empirical results of Tables 5 and 8 suggest that while NREGS has not substantially impacted male private-sector wages, women's wages have increased substantially. This is consistent with the existing evidence of the impacts of the scheme, and is also in line with the gender predictions made by the simple model above. ${ }^{34}$ It also suggests that despite many practical problems, the scheme is being implemented

\footnotetext{
${ }^{33}$ The NREGS year starts on April 1, whereas the NSS household survey data starts in July, so the overlap of both data sources is not perfect.

${ }^{34}$ The somewhat puzzling strong response of private-sector wages despite major rationing issues of NREGS is also found in Dutta et al. (2012).
} 
well enough in Phase 2 districts to force the private sector to react by raising wages for women, since they are especially targeted by NREGS.

\section{Conclusion}

Using a regression discontinuity design, this paper has analyzed the impacts of the Indian National Rural Employment Guarantee Scheme (NREGS) on the rural labor market. The results suggest that male private-sector employment is mostly unaffected by the scheme, whereas NREGS has increased female private-sector casual wages substantially. This supports existing evidence that the scheme is particularly attractive for women. The wage effects are concentrated during the agricultural main season, which is consistent with the idea that wage pressures should be particularly strong during a time when demand for labor is relatively inelastic and NREGS provides a viable outside option. Private-employment outcomes are very imprecisely estimated but may point to some crowding out of private-sector casual jobs.

Overall, these results suggest that NREGS has few negative impacts on the working of casual rural labor markets. One of the main concerns in providing government employment is the possibility of major crowding-out of private job opportunities, making workers reliant on public works employment in the longer run. Such concerns seem mostly unfounded in the Indian case, although the private-sector employment results are not strong enough to rule them out completely. Consistent with anecdotal evidence, the results suggest that households are more likely to take up NREGS employment in the agricultural off-season when there is little alternative wage employment, thereby limiting spillovers to the private sector.

At the same time, however, NREGS in its current form also does not seem to be a silver bullet in the fight against poverty since its positive welfare effects are estimated 
to be relatively modest. The empirical analysis in this paper suggests that the most important function of the scheme may be to indirectly enforce minimum wages in the private sector during the agricultural main season, but may be less successful in providing employment and income for large enough sections of the working-age population during the agricultural off-season when households are especially dependent on additional sources of income. Large-scale rationing of public employment is certainly an important explanation for this outcome that limits the safety-net function of NREGS for the rural poor (see e.g. Dutta et al. 2012). All this implies that the bulk of NREGS' benefits may go to those rural households that have a female working in the private sector during the harvest season, but may not reach many other families willing to do manual work at the minimum wage. Since the government expenditures on NREGS are roughly equal to 1 percent of India's GDP, this raises the question whether the money would be more effectively spent on other anti-poverty measures. More research on the direct and indirect effects of NREGS on the lives of the rural poor is therefore needed to get a better sense of the scheme's total costs and benefits. 


\section{References}

[1] Azam, Mehtabul. 2012. 'The Impact of Indian Job Guarantee Scheme on Labor Market Outcomes: Evidence from a Natural Experiment.' IZA Discussion Paper 6548 .

[2] Basu, Arnab. 2002. 'Oligopsonistic Landlords, Segmented Labor markets, and the Persistence of Tied-Labor Contracts.' American Journal of Agricultural Economics, 84(2): 438-453.

[3] Basu, Arnab. 2011. 'Impact of Rural Employment Guarantee Schemes on Seasonal Labor Markets: Optimum Compensation and Workers' Welfare.' IZA Discussion Paper 5071.

[4] Besley, Timothy, and Stephen Coate. 1992. 'Workfare versus Welfare: Incentive Arguments for Work Requirements in Poverty-Alleviation Programs.' American Economic Review, 82(1): 249-261.

[5] Centre for Science and Environment. 2008. 'An Assessment of the Performance of the National Rural Employment Guarantee Programme in Terms of its Potential for Creation of Natural Wealth in India's Villages.'

[6] Datt, Gaurav, and Martin Ravallion. 1994. 'Transfer Benefits from Public-Works Employment: Evidence from Rural India.' The Economic Journal, 104(427): 13461369.

[7] Dey, Nikhil, Jean Dreze, and Reetika Khera. 2006. Employment Guarantee Act: A Primer. (Delhi: National Book Trust, India)

[8] Dutta, Puja, Murgai, Rinku, Ravallion, Martin, and Dominique van de Walle. 2012. 'Does India's Employment Guarantee Scheme Guarantee Enployment? World Bank Policy Research Working Paper 6003.

[9] Government of India. 2009. 'The National Rural Employment Guarantee Act.'

[10] Imbert, Clement, and John Papp. 2012. 'Equilibrium Distributional Impacts of Government Employment Programs: Evidence of India's Employment Guarantee.' http://www.parisschoolofeconomics.eu/docs/imbert-clement/2012-03-19-pseworking-paper-equilibrium-distributional-impacts-of-government-programs-imbertpapp.pdf.

[11] Institute of Applied Manpower Research. 2007. 'All-India Report on Evaluation of NREGA - A Survey of 20 Districts.'

[12] Jeyaranjan, J. 2011. 'Women and Pro-Poor Policies in Rural Tamil Nadu: An Examination of Practices and Responses.' Economic and Political Weekly, XLVI(43): 64-74. 
[13] Johnson, Doug. 2009a. 'Can Workfare Serve as a Substitute for Weather Insurance? The Case of NREGA in Andhra Pradesh.' Institute for Financial Management and Research, Centre for Micro Finance, Working Paper 32.

[14] Johnson, Doug. 2009b. 'How Do Caste, Gender and Party Affiliation of Locally Elected Leaders Affect Implementation of NREGA?' Institute for Financial Management and Research, Centre for Micro Finance Working Paper 33.

[15] Johnson, Doug, Ajay Tannirkulam, and Caroline Laroche. 2009. 'NREGA in Andhra Pradesh - Seven Lessons from the Data.' Centre for Micro Finance Focus Note.

[16] Kaur, Supreet. 2012. 'Nominal Wage Rigidity in Village Labor Markets.' http://www.people.fas.harvard.edu/ kaur/papers/Kaur ${ }_{J} M P_{W}$ ageRigidity.pdf.

[17] Khera, Reetika. 2009. 'Group Measurement of NREGA Work: The Jalore Experiment.' Centre for Development Economics Delhi School of Economics Working Paper 180.

[18] Khera, Reetika, and Nandini Nayak. 2009. 'Women Workers and Perceptions of the National Rural Employment Guarantee Act.' Economic and Political Weekly, XLIV(43): 49-57.

[19] Kluve, Jochen. 2010. 'The effectiveness of European active labor market programs.' Labour Economics, 17(6): 904-918.

[20] Lal, Radhika, Steve Miller, Maikel Lieuw-Kie-Song, and Daniel Kostzer. 2010. 'Public Works and Employment Programmes: Towards a Long-Term Development Approach.' International Policy Centre for Inclusive Growth Working Paper 66.

[21] Lee, David S. 2008. 'Randomized Experiments from Non-Random Selection in U.S. House Elections.' Journal of Econometrics, 142(2): 675-697.

[22] Lee, David S., and Thomas Lemieux. 2009. 'Regression Discontinuity Designs in Economics.' NBER Working Paper 14723.

[23] McCrary, Justin. 2008. 'Manipulation of the Running Variable in the Regression Discontinuity Design: A Density Test.' Journal of Econometrics, 142(2): 698-714.

[24] Ministry of Rural Development, Department of Rural Development, Government of India. 2010. 'Mahatma Gandhi National Rural Employment Guarantee Act 2005 - Report to the People 2nd Feb 2006 - 2nd Feb 2010.'

[25] Narayanan, Sudha. 2008. 'Employment Guarantee, Women's Work and Childcare.' Economic and Political Weekly, XLIII(9): 10-13.

[26] NCAER-PIF. 2009. 'Evaluating the performance of the National Rural Employment Guarantee Act.' 
[27] Niehaus, Paul, and Sandip Sukhtankar. 2012a. 'The Marginal Rate of Corruption in Public Programs.' http://www.dartmouth.edu/ sandip/niehaus-sukhtankar-marginalcorruption.pdf.

[28] Niehaus, Paul, and Sandip Sukhtankar. 2012b. 'Corruption Dynamics: The Golden Goose Effect.' http://www.dartmouth.edu/ sandip/niehaus-sukhtankar-goldengoose.pdf.

[29] Planning Commission. 2003. 'Report of the Task Force: Identification of Districts for Wage and Self Employment Programmes.'

[30] Planning Commission (MLP Division). 2003. 'Backward Districts Initiative - Rashtriya Sam Vikas Yojana - The Scheme and Guidelines for Preparation of District Plans.'

[31] Samarthan Centre for Development Support. 2007. 'Status of NREGA Implementation: Grassroots Learning and Ways Forward - 1st Monitoring Report.'

[32] Subbarao, K. 1997. 'Public Works as an Anti-Poverty Program: An Overview of CrossCountry Experience.' American Journal of Agricultural Economics, 79(2): 678-683. 
Table 1: Prediction Success of Algorithm for Major Indian States

\begin{tabular}{ccccc} 
& \multicolumn{2}{c}{ Phase 1 } & \multicolumn{2}{c}{ Phase 2 } \\
\cline { 2 - 5 } & NREGS & non-pred & NREGS & non-pred \\
\hline Andhra Pradesh & 13 & 1 & 6 & 1 \\
Assam & 7 & 0 & 6 & 3 \\
Bihar & 23 & 1 & 15 & 0 \\
Chhattisgarh & 11 & 1 & 4 & 1 \\
Gujarat & 6 & 2 & 3 & 0 \\
Haryana & 2 & 2 & 1 & 0 \\
Jharkhand & 20 & 0 & 2 & 0 \\
Karnataka & 5 & 1 & 6 & 5 \\
Kerala & 2 & 1 & 2 & 0 \\
Madhya Pradesh & 18 & 4 & 13 & 5 \\
Maharashtra & 12 & 1 & 6 & 2 \\
Orissa & 19 & 1 & 5 & 0 \\
Punjab & 1 & 0 & 3 & 1 \\
Rajasthan & 6 & 1 & 6 & 4 \\
Tamil Nadu & 6 & 2 & 4 & 0 \\
Uttar Pradesh & 22 & 2 & 17 & 3 \\
West Bengal & 10 & 2 & 7 & 0 \\
Total & 183 & 22 & 106 & 25 \\
\hline
\end{tabular}

Note: Columns 1 and 3 give the number of treatment districts allocated to a state in a given phase of NREGS rollout. Columns 2 and 4 give the number of districts in a given state and phase whose treatment status is incorrectly predicted by the proposed algorithm. The proposed algorithm states that the number of treatment districts a state is assigned in a given phase should be filled with the least developed districts according to the Indian Planning Commission's ranking of districts (Planning Commission 2003). In the first phase, districts on an existing official list of districts majorly affected by left-wing terrorism were prioritized regardless of their rank. 
Table 2A: Summary Statistics for Districts at Baseline by Phase (Men)

\begin{tabular}{ccccccc} 
& \multicolumn{2}{c}{ phase 1} & \multicolumn{2}{c}{ phase 2} & \multicolumn{2}{c}{ phase 3 } \\
& & $\mathrm{N}$ & & $\mathrm{N}$ & & $\mathrm{N}$ \\
\hline private employment & 0.3106 & 703 & 0.2975 & 396 & 0.2938 & 668 \\
family employment & 0.5768 & 703 & 0.5810 & 396 & 0.5271 & 668 \\
public employment & 0.0028 & 703 & 0.0038 & 396 & 0.0015 & 668 \\
daily wage & 47.46 & 680 & 52.75 & 387 & 65.71 & 645 \\
daily wage private & 46.62 & 680 & 52.77 & 386 & 65.78 & 645 \\
daily wage public & 86.72 & 33 & 53.44 & 18 & 63.54 & 22 \\
\hline
\end{tabular}

Table 2B: Summary Statistics for Districts at Baseline by Phase (Women) phase $1 \quad$ phase 2 phase 3

\begin{tabular}{ccccccc} 
& & $\mathrm{N}$ & & $\mathrm{N}$ & & $\mathrm{N}$ \\
\hline private employment & 0.1592 & 703 & 0.1397 & 396 & 0.1332 & 668 \\
family employment & 0.3313 & 703 & 0.2559 & 396 & 0.3281 & 668 \\
public employment & 0.0014 & 703 & 0.0028 & 396 & 0.0013 & 668 \\
daily wage & 34.04 & 569 & 38.19 & 306 & 45.93 & 504 \\
daily wage private & 33.99 & 568 & 37.69 & 303 & 45.76 & 497 \\
daily wage public & 45.46 & 12 & 53.42 & 12 & 52.32 & 17 \\
\hline
\end{tabular}

Note: An observation here is a district with non-missing Planning Commission rank in a given season in the baseline data (July 2004-June 2005). Summary statistics are calculated from aggregated and weighted individual NSS data. 
Table 3: NREGS impact: public employment (men)

\begin{tabular}{|c|c|c|c|c|}
\hline & (1) & $(2)$ & (3) & $(4)$ \\
\hline \multirow[t]{2}{*}{ NREGS } & 0.0010 & -0.0003 & -0.0014 & 0.0040 \\
\hline & $(.0081)$ & $(.0081)$ & $(.0087)$ & $(.0124)$ \\
\hline lower CI & -0.0148 & -0.0162 & -0.0183 & -0.0204 \\
\hline upper CI & 0.0168 & 0.0156 & 0.0156 & 0.0283 \\
\hline R-squared & 0.0651 & 0.0541 & 0.0609 & \\
\hline $\mathrm{N}$ & 1063 & 1063 & 1063 & 1063 \\
\hline outcome mean & 0.0069 & 0.0069 & 0.0069 & 0.0069 \\
\hline F stat first stage & 208.88 & 130.74 & 188.97 & 114.09 \\
\hline state FE & Yes & Yes & Yes & Yes \\
\hline polynomial order & 1 & 1 & 2 & 2 \\
\hline flexible slope & No & Yes & No & Yes \\
\hline
\end{tabular}

Robust standard errors for clustering at district level in parenthesis. An observation is a district in a given season. The outcome variable is the mean public employment proportion of working-age adults (18-60) with at most secondary education in the rural areas of a district. The specifications are parametric regressions with different levels of flexibility. The treatment indicator NREGS is instrumented with the predicted treatment status based on the proposed algorithm. 
Table 4: NREGS impact: private employment (men)

\begin{tabular}{lcccc} 
& $(1)$ & $(2)$ & $(3)$ & $(4)$ \\
\hline NREGS & -0.0283 & -0.0315 & -0.0432 & -0.0716 \\
& $(.0353)$ & $(.0357)$ & $(.0359)$ & $(.0455)$ \\
lower CI & -0.0975 & -0.1014 & -0.1136 & -0.1608 \\
upper CI & 0.0409 & 0.0384 & 0.0272 & 0.0175 \\
R-squared & 0.2743 & 0.2719 & 0.2723 & 0.2104 \\
$\mathrm{~N}$ & 1063 & 1063 & 1063 & 1063 \\
outcome mean & 0.3279 & 0.3279 & 0.3279 & 0.3279 \\
F stat first stage & 208.88 & 130.74 & 188.97 & 114.09 \\
state FE & Yes & Yes & Yes & Yes \\
polynomial order & 1 & 1 & 2 & 2 \\
flexible slope & No & Yes & No & Yes \\
\hline Note: $* * * \mathrm{p}<0.01, * *$ & $\mathrm{p}<0.05, * \mathrm{p}<0.1$ & &
\end{tabular}

Robust standard errors for clustering at district level in parenthesis. An observation is a district in a given season. The outcome variable is the mean casual private employment proportion of working-age adults (18-60) with at most secondary education in the rural areas of a district. The specifications are parametric regressions with different levels of flexibility. The treatment indicator NREGS is instrumented with the predicted treatment status based on the proposed algorithm. 
Table 5: NREGS impact: private wage (men)

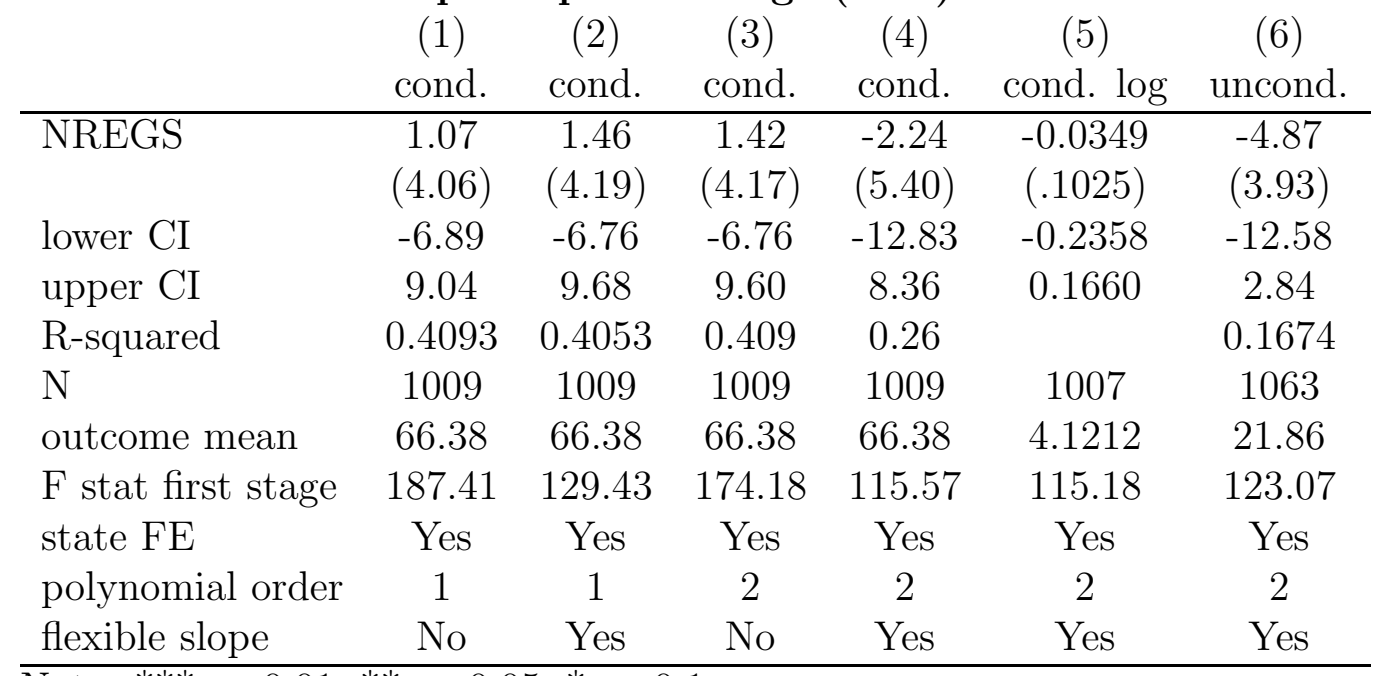

Note: ${ }^{* * *} \mathrm{p}<0.01,{ }^{* *} \mathrm{p}<0.05,{ }^{*} \mathrm{p}<0.1$

Robust standard errors for clustering at district level in parenthesis. An observation is a district in a given season. The outcome variable is the mean daily casual privatesector wage of working-age adults (18-60) with at most secondary education in the rural areas of a district. The specifications are parametric regressions with different levels of flexibility. The treatment indicator NREGS is instrumented with the predicted treatment status based on the proposed algorithm. The wage in columns 1-4 is the absolute wage conditional on private-sector employment in the last 7 days, whereas it is the conditional log wage in column 5. Column 6 uses the unconditional absolute wage. 
Table 6: NREGS impact: public employment (women)

\begin{tabular}{|c|c|c|c|c|}
\hline & (1) & $(2)$ & $(3)$ & (4) \\
\hline \multirow[t]{2}{*}{ NREGS } & 0.0034 & 0.0033 & 0.0029 & 0.0038 \\
\hline & $(.0084)$ & $(.0083)$ & $(.0087)$ & $(.0147)$ \\
\hline lower CI & -0.0131 & -0.0130 & -0.0142 & -0.0250 \\
\hline upper CI & 0.0199 & 0.0195 & 0.0200 & 0.0325 \\
\hline R-squared & 0.1407 & 0.1408 & 0.14 & \\
\hline $\mathrm{N}$ & 1063 & 1063 & 1063 & 1063 \\
\hline outcome mean & 0.0053 & 0.0053 & 0.0053 & 0.0053 \\
\hline F stat first stage & 211.22 & 156.4 & 197.35 & 129.03 \\
\hline state FE & Yes & Yes & Yes & Yes \\
\hline polynomial order & 1 & 1 & 2 & 2 \\
\hline flexible slope & No & Yes & No & Yes \\
\hline
\end{tabular}

Robust standard errors for clustering at district level in parenthesis. An observation is a district in a given season. The outcome variable is the mean public employment proportion of working-age adults (18-60) with at most secondary education in the rural areas of a district. The specifications are parametric regressions with different levels of flexibility. The treatment indicator NREGS is instrumented with the predicted treatment status based on the proposed algorithm. 
Table 7: NREGS impact: private employment (women)

\begin{tabular}{lcccc} 
& $(1)$ & $(2)$ & $(3)$ & $(4)$ \\
\hline NREGS & -0.0113 & -0.0107 & -0.0138 & -0.0317 \\
& $(.0272)$ & $(.0277)$ & $(.0279)$ & $(.0296)$ \\
lower CI & -0.0646 & -0.0650 & -0.0685 & -0.0896 \\
upper CI & 0.0420 & 0.0436 & 0.0410 & 0.0263 \\
R-squared & 0.4457 & 0.446 & 0.4455 & 0.4398 \\
$\mathrm{~N}$ & 1063 & 1063 & 1063 & 1063 \\
outcome mean & 0.1309 & 0.1309 & 0.1309 & 0.1309 \\
F stat first stage & 211.22 & 156.4 & 197.35 & 129.03 \\
state FE & Yes & Yes & Yes & Yes \\
polynomial order & 1 & 1 & 2 & 2 \\
flexible slope & No & Yes & No & Yes \\
\hline Note: $* * * \mathrm{p}<0.01, * *$ & $\mathrm{p}<0.05, * \mathrm{p}<0.1$ & &
\end{tabular}

Robust standard errors for clustering at district level in parenthesis. An observation is a district in a given season. The outcome variable is the mean casual private employment proportion of working-age adults (18-60) with at most secondary education in the rural areas of a district. The specifications are parametric regressions with different levels of flexibility. The treatment indicator NREGS is instrumented with the predicted treatment status based on the proposed algorithm. 
Table 8: NREGS impact: private wage (women)

\begin{tabular}{|c|c|c|c|c|c|c|}
\hline & $\begin{array}{l}(1) \\
\text { cond. }\end{array}$ & $\begin{array}{l}(2) \\
\text { cond. }\end{array}$ & $\begin{array}{l}(3) \\
\text { cond. }\end{array}$ & $\begin{array}{l}(4) \\
\text { cond. }\end{array}$ & $\begin{array}{l}\text { (5) } \\
\text { cond. } \log \end{array}$ & $\begin{array}{c}(6) \\
\text { uncond. }\end{array}$ \\
\hline NREGS & $\begin{array}{l}10.49^{*} \\
(6.32)\end{array}$ & $\begin{array}{l}10.40^{*} \\
(6.22)\end{array}$ & $\begin{array}{l}11.37 \\
(6.94)\end{array}$ & $\begin{array}{l}8.70^{*} \\
(5.30)\end{array}$ & $\begin{array}{l}0.2075^{*} \\
(.1224)\end{array}$ & $\begin{array}{l}-0.93 \\
(1.52)\end{array}$ \\
\hline lower CI & -1.90 & -1.79 & -2.24 & -1.68 & -0.0324 & -3.91 \\
\hline upper CI & 22.89 & 22.59 & 24.97 & 19.08 & 0.4475 & 2.05 \\
\hline R-squared & 0.1965 & 0.1913 & 0.1928 & 0.1703 & 0.2196 & 0.1745 \\
\hline $\mathrm{N}$ & 663 & 663 & 663 & 663 & 656 & 1063 \\
\hline outcome mean & 43.50 & 43.50 & 43.50 & 43.50 & 3.6488 & 5.10 \\
\hline F stat first stage & 34421.81 & 283.23 & 838.25 & 174.59 & 204.16 & 127.69 \\
\hline state FE & Yes & Yes & Yes & Yes & Yes & Yes \\
\hline polynomial order & 1 & 1 & 2 & 2 & 2 & 2 \\
\hline flexible slope & No & Yes & No & Yes & Yes & Yes \\
\hline
\end{tabular}

Note: ${ }^{* * *} \mathrm{p}<0.01,{ }^{* *} \mathrm{p}<0.05,{ }^{*} \mathrm{p}<0.1$

Robust standard errors for clustering at district level in parenthesis. An observation is a district in a given season. The outcome variable is the mean daily casual privatesector wage of working-age adults (18-60) with at most secondary education in the rural areas of a district. The specifications are parametric regressions with different levels of flexibility. The treatment indicator NREGS is instrumented with the predicted treatment status based on the proposed algorithm. The wage in columns 1-4 is the absolute wage conditional on private-sector employment in the last 7 days, whereas it is the conditional $\log$ wage in column 5 . Column 6 uses the unconditional absolute wage. 
Table 9: Seasonality: public employment (women)

\begin{tabular}{|c|c|c|c|c|}
\hline & (1) & (2) & $(3)$ & (4) \\
\hline \multirow[t]{2}{*}{ NREGS } & -0.0017 & -0.0047 & -0.0022 & 0.0129 \\
\hline & $(.0061)$ & $(.0060)$ & $(.0064)$ & $(.0176)$ \\
\hline \multirow[t]{2}{*}{ NREGS*dry season } & 0.0103 & 0.0161 & 0.0103 & -0.0192 \\
\hline & $(.0070)$ & $(.0108)$ & $(.0070)$ & $(.0191)$ \\
\hline lower CI & -0.0137 & -0.0164 & -0.0148 & -0.0215 \\
\hline upper CI & 0.0103 & 0.0070 & 0.0104 & 0.0473 \\
\hline lower CI dry & -0.0035 & -0.0050 & -0.0035 & -0.0567 \\
\hline upper CI dry & 0.0241 & 0.0372 & 0.0241 & 0.0182 \\
\hline R-squared & 0.1604 & 0.1576 & 0.1597 & \\
\hline $\mathrm{N}$ & 1063 & 1063 & 1063 & 1063 \\
\hline outcome mean & 0.0053 & 0.0053 & 0.0053 & 0.0053 \\
\hline F stat first stage & 198.48 & 141.51 & 186.72 & 111.27 \\
\hline state FE & Yes & Yes & Yes & Yes \\
\hline polynomial order & 1 & 1 & 2 & 2 \\
\hline flexible slope & No & Yes & No & Yes \\
\hline
\end{tabular}

Note: ${ }^{* * *} \mathrm{p}<0.01,{ }^{* *} \mathrm{p}<0.05,{ }^{*} \mathrm{p}<0.1$

Robust standard errors for clustering at district level in parenthesis. An observation is a district in a given season. The outcome variable is the mean public employment proportion of working-age adults (18-60) with at most secondary education in the rural areas of a district. The specifications are parametric regressions with different levels of flexibility. The treatment indicator NREGS is instrumented with the predicted treatment status based on the proposed algorithm. 
Table 10: Seasonality: private wage (women)

\begin{tabular}{lcccccc} 
& $(1)$ & $(2)$ & $(3)$ & $(4)$ & $(5)$ & $(6)$ \\
& cond. & cond. & cond. & cond. & cond. log & uncond. \\
\hline NREGS & $18.78^{* *}$ & $19.03^{* *}$ & $19.63^{* *}$ & $21.78^{* *}$ & $0.3970^{* *}$ & 0.44 \\
& $(7.41)$ & $(8.55)$ & $(8.01)$ & $(10.62)$ & $(.1967)$ & $(2.21)$ \\
NREGS*dry season & $-16.21^{* * *}$ & $-17.00^{* *}$ & $-16.10^{* * *}$ & -25.16 & -0.3574 & -2.71 \\
& $(4.95)$ & $(8.40)$ & $(4.91)$ & $(17.07)$ & $(.3009)$ & $(3.05)$ \\
lower CI & 4.25 & 2.27 & 3.94 & 0.97 & 0.0114 & -3.90 \\
upper CI & 33.31 & 35.80 & 35.33 & 42.59 & 0.7826 & 4.78 \\
lower CI dry & -25.91 & -33.46 & -25.72 & -58.62 & -0.9471 & -8.68 \\
upper CI dry & -6.52 & -0.54 & -6.48 & 8.29 & 0.2323 & 3.26 \\
R-squared & 0.2197 & 0.2139 & 0.2161 & 0.1533 & 0.2337 & 0.1461 \\
N & 663 & 663 & 663 & 663 & 656 & 1063 \\
outcome mean & 43.50 & 43.50 & 43.50 & 43.50 & 3.6488 & 5.10 \\
F stat first stage & 9543.98 & 262.13 & 841.47 & 157.21 & 154.52 & 109.86 \\
state FE & Yes & Yes & Yes & Yes & Yes & Yes \\
polynomial order & 1 & 1 & 2 & 2 & 2 & 2 \\
flexible slope & No & Yes & No & Yes & Yes & Yes \\
\hline Note: $* * *$ p $<0.01, * *$ & ${ }^{*}<0.05, *$ & $* 0.1$ & & & &
\end{tabular}

Note: ${ }^{* * *} \mathrm{p}<0.01,{ }^{* *} \mathrm{p}<0.05,{ }^{*} \mathrm{p}<0.1$

Robust standard errors for clustering at district level in parenthesis. An observation is a district in a given season. The outcome variable is the mean daily casual privatesector wage of working-age adults (18-60) with at most secondary education in the rural areas of a district. The specifications are parametric regressions with different levels of flexibility. The treatment indicator NREGS is instrumented with the predicted treatment status based on the proposed algorithm. The wage in columns 1-4 is the absolute wage conditional on private-sector employment in the last 7 days, whereas it is the conditional log wage in column 5. Column 6 uses the unconditional absolute wage. 
Figure 1: Number of observations per state rank for Phase 2

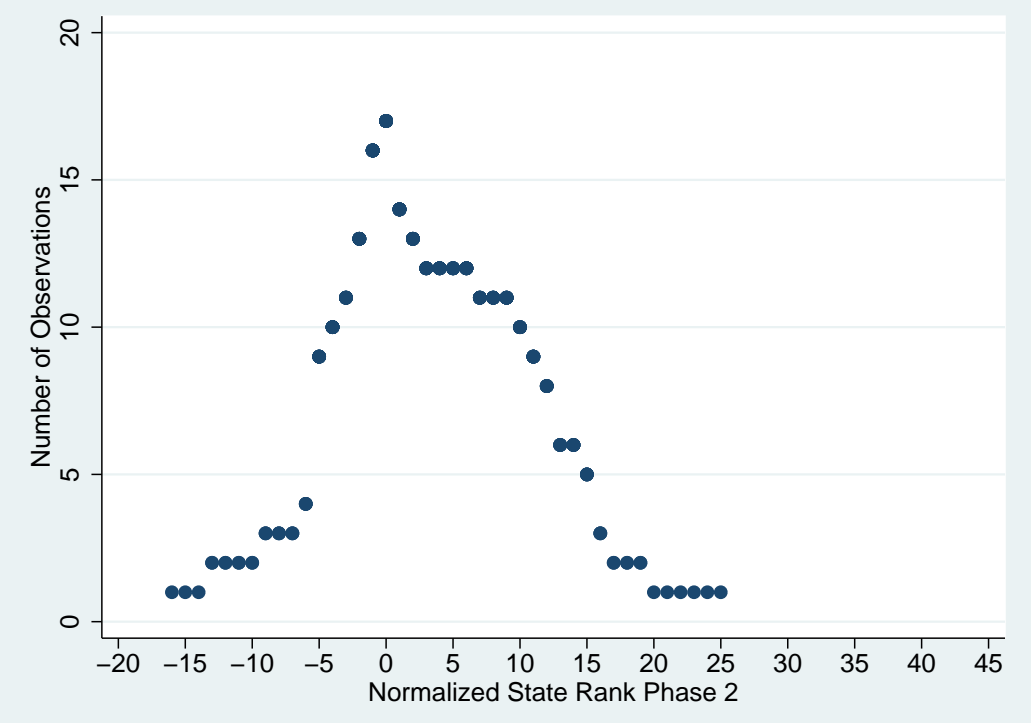

Note: Figure 1 excludes Phase 1 districts. Planning Commission ranks are made statespecific and normalized such that the last district eligible for receiving NREGS in Phase 2 according to the proposed algorithm has a rank of 0 . Districts with positive ranks should be ineligible for the program.

Figure 2: General Distribution of Index over Ranks

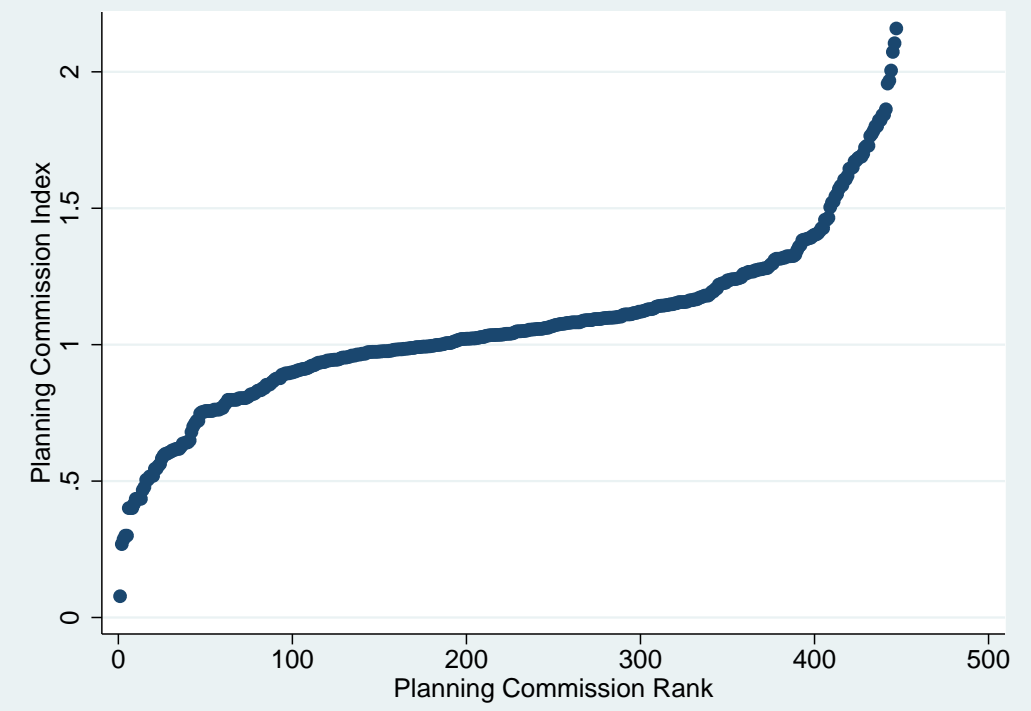


Figure 3: Distribution of Index over State-Specific Ranks (Phase 2 vs Phase 3)

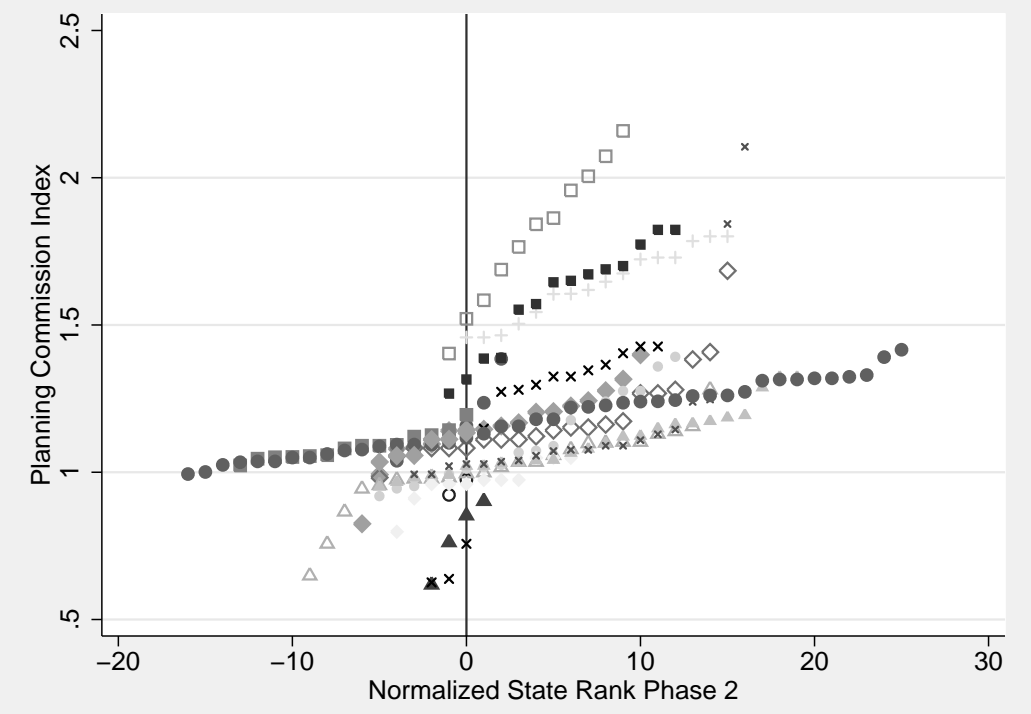

Figure 4: Discontinuity of treatment status for Phase 2

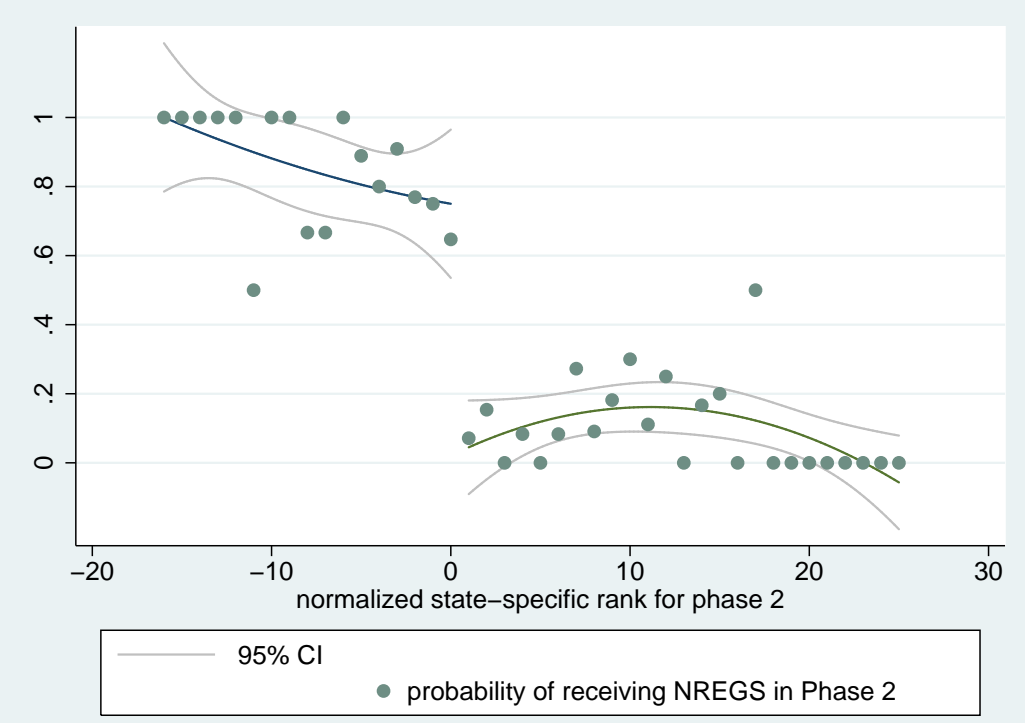

Note: Figure 4 excludes Phase 1 districts. The used bin size is 1 , so each individual rank. 
Figure 5: NREGS impact on male public employment, extensive margin

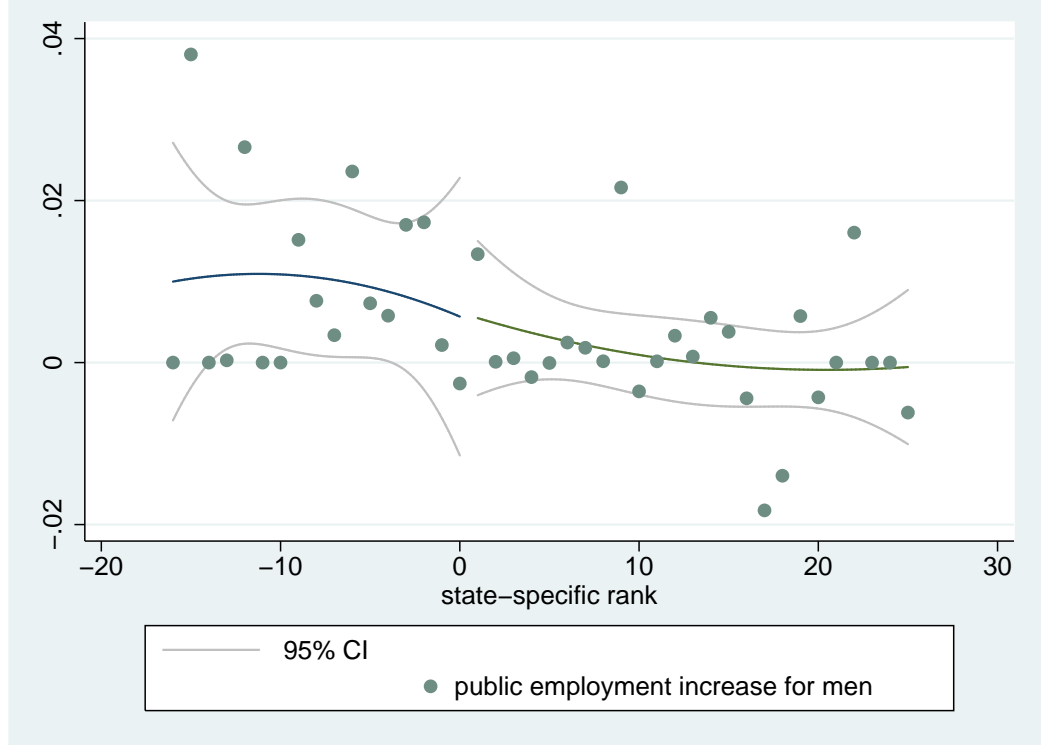

Note: Outcome variable is difference of outcome values and baseline values. An observation is the average district-level change at a given rank.

Figure 6: NREGS impact on male private wage, extensive margin

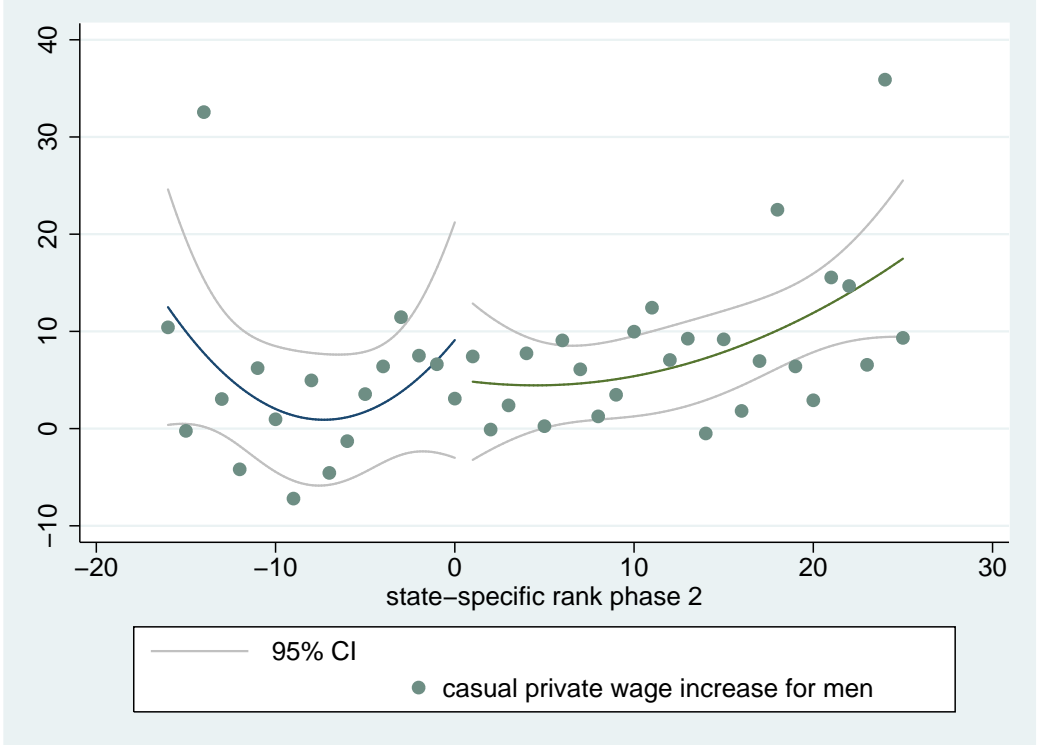

Note: Outcome variable is difference of outcome values and baseline values. An observation is the average district-level change at a given rank. 
Figure 7: NREGS impact on female public employment, extensive margin

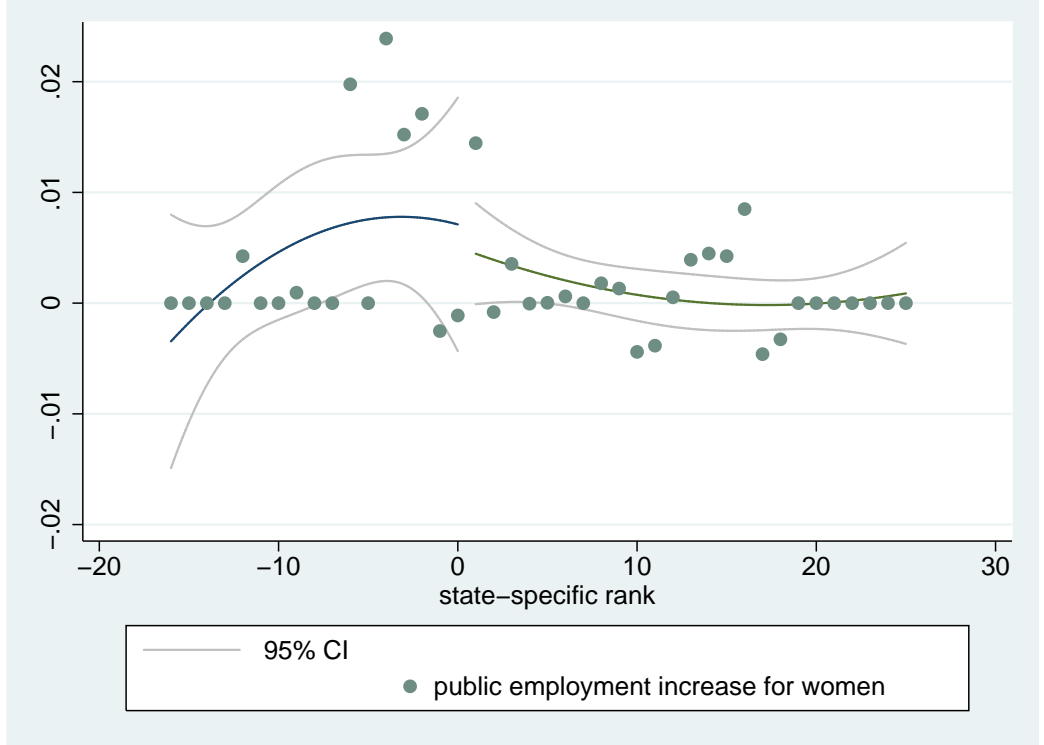

Note: Outcome variable is difference of outcome values and baseline values. An observation is the average district-level change at a given rank.

Figure 8: NREGS impact on female private wage, extensive margin

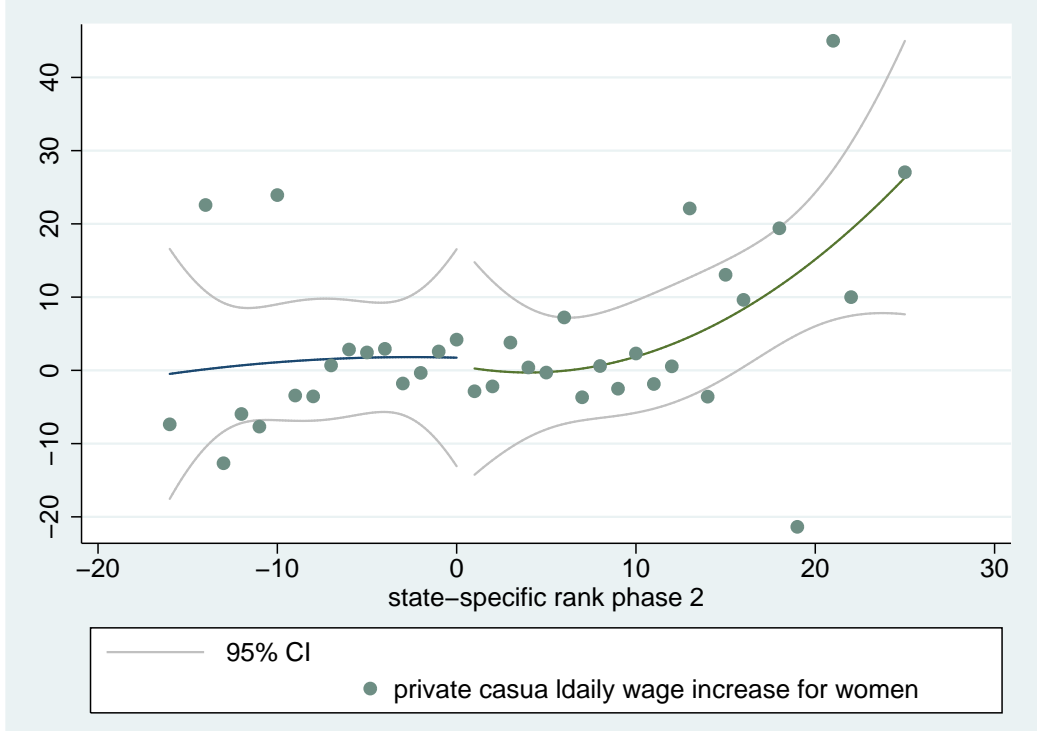

Note: Outcome variable is difference of outcome values and baseline values. An observation is the average district-level change at a given rank. 


\section{Appendix}

Table A1: public employment (men, Phase 1 vs Phase 2)

\begin{tabular}{lcccc} 
& $(1)$ & $(2)$ & $(3)$ & $(4)$ \\
\hline NREGS Phase 1 & -0.0023 & -0.0026 & -0.0039 & 0.0058 \\
& $(.0107)$ & $(.0109)$ & $(.0117)$ & $(.0162)$ \\
lower CI & -0.0232 & -0.0240 & -0.0267 & -0.0259 \\
upper CI & 0.0186 & 0.0188 & 0.0189 & 0.0375 \\
R-squared & 0.065 & 0.0648 & 0.0664 & \\
$\mathrm{~N}$ & 988 & 988 & 988 & 988 \\
outcome mean & 0.0122 & 0.0122 & 0.0122 & 0.0122 \\
F stat first stage & 16.4 & 19.07 & 19.41 & 19.72 \\
state FE & Yes & Yes & Yes & Yes \\
polynomial order & 1 & 1 & 2 & 2 \\
flexible slope & No & Yes & No & Yes \\
\hline Note:
\end{tabular}


Table A2: private wage (men, Phase 1 vs Phase 2)

\begin{tabular}{lcccccc} 
& $(1)$ & $(2)$ & $(3)$ & $(4)$ & $(5)$ & $(6)$ \\
& cond. & cond. & cond. & cond. & cond. log & uncond. \\
\hline NREGS Phase 1 & -1.31 & -1.37 & -0.80 & 2.68 & 0.0368 & -0.85 \\
& $(4.66)$ & $(4.78)$ & $(4.88)$ & $(6.96)$ & $(.1162)$ & $(4.58)$ \\
lower CI & -10.44 & -10.73 & -10.36 & -10.96 & -0.1909 & -9.83 \\
upper CI & 7.82 & 8.00 & 8.76 & 16.31 & 0.2645 & 8.12 \\
R-squared & 0.4044 & 0.4031 & 0.4057 & 0.3748 & 0.3794 & 0.3408 \\
N & 934 & 934 & 934 & 934 & 934 & 988 \\
outcome mean & 55.40 & 55.40 & 55.40 & 55.40 & 3.9512 & 18.36 \\
F stat first stage & 16.19 & 20.1 & 20.62 & 20.94 & 20.05 & 19.74 \\
state FE & Yes & Yes & Yes & Yes & Yes & Yes \\
polynomial order & 1 & 1 & 2 & 2 & 2 & 2 \\
flexible slope & No & Yes & No & Yes & Yes & Yes \\
\hline
\end{tabular}

Note: ${ }^{* * *} \mathrm{p}<0.01,{ }^{* *} \mathrm{p}<0.05,{ }^{*} \mathrm{p}<0.1$

Robust standard errors for clustering at district level in parenthesis. An observation is a district in a given season. The outcome variable is the mean daily casual privatesector wage of working-age adults (18-60) with at most secondary education in the rural areas of a district. The specifications are parametric regressions with different levels of flexibility. The treatment indicator NREGS is instrumented with the predicted treatment status based on the proposed algorithm. The wage in columns 1-4 is the absolute wage conditional on private-sector employment in the last 7 days, whereas it is the conditional log wage in column 5. Column 6 uses the unconditional absolute wage. 
Table A3: public employment(women, Phase 1 vs Phase 2)

\begin{tabular}{|c|c|c|c|c|}
\hline & (1) & (2) & $(3)$ & (4) \\
\hline \multirow{2}{*}{ NREGS Phase 1} & -0.0098 & -0.0095 & -0.0093 & -0.0118 \\
\hline & $(.0125)$ & $(.0125)$ & $(.0128)$ & $(.0194)$ \\
\hline lower CI & -0.0342 & -0.0339 & -0.0344 & -0.0497 \\
\hline upper CI & 0.0146 & 0.0149 & 0.0158 & 0.0261 \\
\hline R-squared & 0.1244 & 0.1247 & 0.1247 & 0.1053 \\
\hline $\mathrm{N}$ & 988 & 988 & 988 & 988 \\
\hline outcome mean & 0.0071 & 0.0071 & 0.0071 & 0.0071 \\
\hline F stat first stage & 17.46 & 20.92 & 21.63 & 19.25 \\
\hline state FE & Yes & Yes & Yes & Yes \\
\hline polynomial order & 1 & 1 & 2 & 2 \\
\hline flexible slope & No & Yes & No & Yes \\
\hline
\end{tabular}


Table A4: private wage (women, Phase 1 vs Phase 2)

\begin{tabular}{lcccccc} 
& $(1)$ & $(2)$ & $(3)$ & $(4)$ & $(5)$ & $(6)$ \\
& cond. & cond. & cond. & cond. & cond. log & uncond. \\
\hline NREGS Phase 1 & -3.28 & -2.04 & -3.70 & -18.14 & -0.3382 & 0.77 \\
& $(5.56)$ & $(5.14)$ & $(5.24)$ & $(17.33)$ & $(.4014)$ & $(2.10)$ \\
lower CI & -14.18 & -12.12 & -13.96 & -52.10 & -1.1249 & -3.34 \\
upper CI & 7.62 & 8.03 & 6.57 & 15.82 & 0.4485 & 4.88 \\
R-squared & 0.2183 & 0.2139 & 0.2324 & & & 0.2723 \\
N & 686 & 686 & 686 & 686 & 675 & 988 \\
outcome mean & 36.36 & 36.36 & 36.36 & 36.36 & 3.4999 & 5.22 \\
F stat first stage & 128.91 & 164.92 & 163.88 & 175.77 & 9137.98 & 20.26 \\
state FE & Yes & Yes & Yes & Yes & Yes & Yes \\
polynomial order & 1 & 1 & 2 & 2 & 2 & 2 \\
flexible slope & No & Yes & No & Yes & Yes & Yes \\
\hline \hline
\end{tabular}

Note: ${ }^{* * *} \mathrm{p}<0.01,{ }^{* *} \mathrm{p}<0.05,{ }^{*} \mathrm{p}<0.1$

Robust standard errors for clustering at district level in parenthesis. An observation is a district in a given season. The outcome variable is the mean daily casual privatesector wage of working-age adults (18-60) with at most secondary education in the rural areas of a district. The specifications are parametric regressions with different levels of flexibility. The treatment indicator NREGS is instrumented with the predicted treatment status based on the proposed algorithm. The wage in columns 1-4 is the absolute wage conditional on private-sector employment in the last 7 days, whereas it is the conditional log wage in column 5. Column 6 uses the unconditional absolute wage. 
Figure 9: Number of observations per state rank for Phase 1

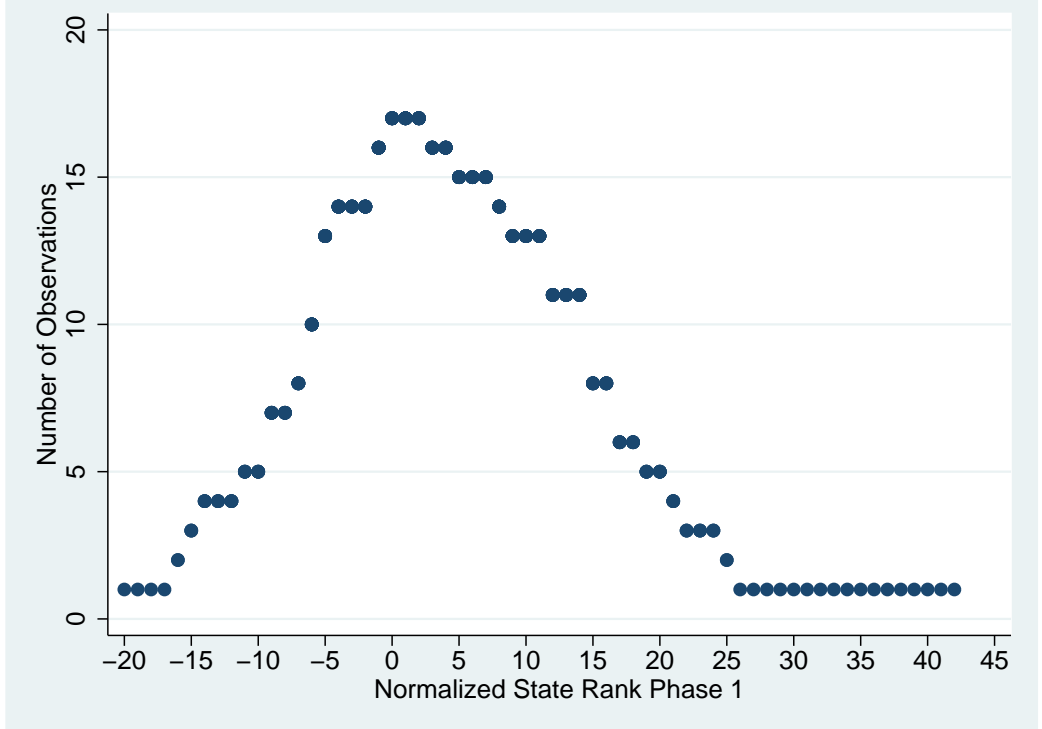

Figure 10: Distribution of Index over State-Specific Ranks (Phase 1 vs the Rest)

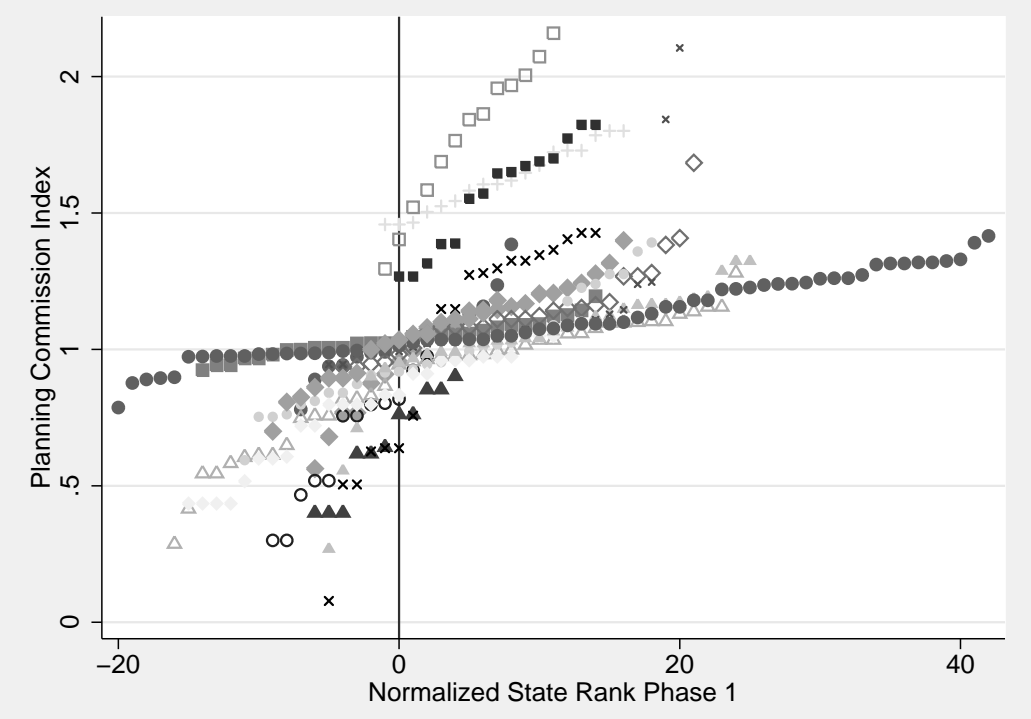


Figure 11: Discontinuity of treatment status for Phase 1

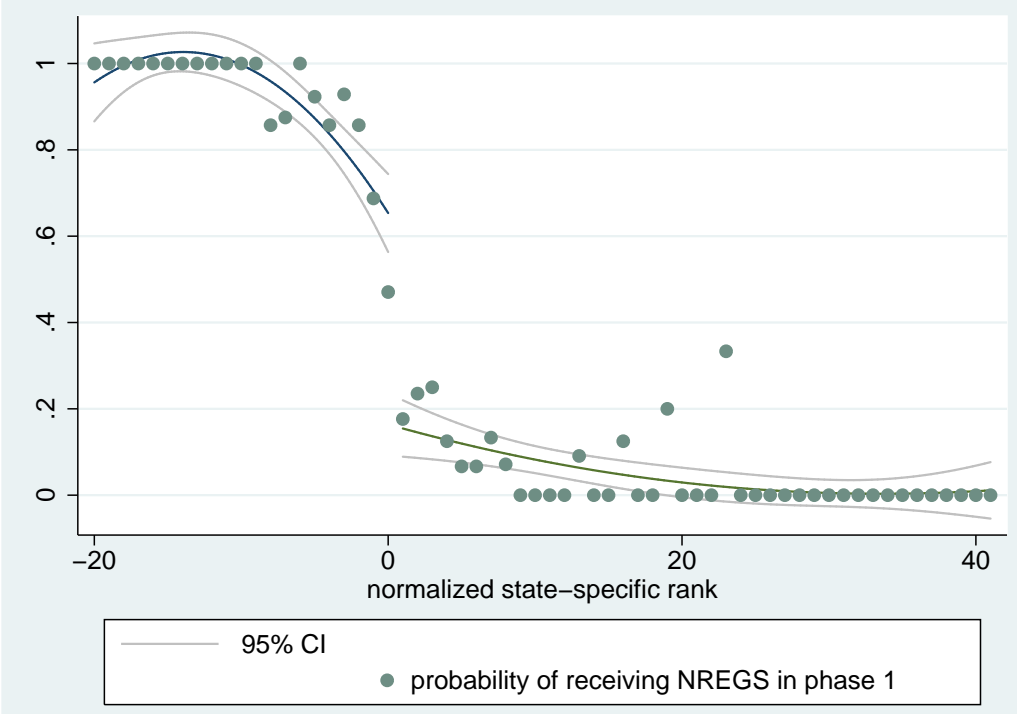

